\title{
POTENCIALIDADES E OPORTUNIDADES NA QUÍMICA DA SACAROSE E OUTROS AÇÚCARES
}

\author{
Vitor Francisco Ferreira* e David Rodrigues da Rocha \\ Departamento de Química Orgânica, Universidade Federal Fluminense, Campus do Valonguinho, 24020-141 Niterói - RJ, Brasil \\ Fernando de Carvalho da Silva \\ Instituto de Química, CT, Bloco A, Universidade Federal do Rio de Janeiro, Cidade Universitária, 21949-900 Rio de Janeiro - RJ, Brasil
}

Recebido em 15/1/09; aceito em 20/3/09; publicado na web em 2/4/09

\begin{abstract}
POTENTIALITY AND OPPORTUNITY IN THE CHEMISTRY OF SUCROSE AND OTHER SUGARS. Non-renewable biomass, such as coal, oil and natural gas are not only energy sources but also important starting materials for the production of a variety of chemicals ranging from gasoline, diesel oil and fine chemicals. In this regard, carbohydrates, the most abundant class of enantiopure organic compounds, are very suitable for generation of chemicals of great practical value. Their bulk-scale availability associated with low cost make them unique starting materials for organic preparative purpose. They are a most attractive alternative for construction of enantiopure target molecules by asymmetric synthesis. This review addresses, in addition to the use of low molecular weight carbohydrates, issues related to renewable biomass from photosynthesis and alternatives for the production of bulk and fine chemicals.
\end{abstract}

Keywords: renewable biomass; sucrose; carbohydrates.

\section{INTRODUÇÃO}

A biomassa renovável terrestre é constituída de diversos produtos de baixas e altas massas moleculares como, por exemplo, carboidratos, aminoácidos, lipídios, e biopolímeros, como celulose, hemicelulose, quitina, amido, lignina e proteínas. Estas biomassas são utilizadas na alimentação e para a produção de uma variedade de combustíveis, produtos químicos e produtos energéticos. O processamento da biomassa renovável abrange métodos biológicos, térmicos e/ou transformações químicas, além de tratamento mecânico para obter combustíveis sólidos, líquidos ou gasosos ou ainda produtos químicos de maior valor agregado.

As biomassas não-renováveis, como carvão, petróleo e gás natural não são apenas materiais energéticos naturais, mas também são importantes insumos para a produção de uma grande variedade de produtos químicos que variam desde gasolina e óleo diese $\mathrm{l}^{1-3} \mathrm{a}$ insumos químicos e intermediários de produtos da química fina. ${ }^{4,5}$ Em termos energéticos, estas três biomassas são responsáveis por aproximadamente $75 \%$ da energia consumida correspondendo a 33, 24 e $19 \%$, respectivamente. ${ }^{6}$ No entanto, como são recursos naturais fósseis finitos, fica evidente a grande necessidade de se desenvolver tecnologia para o aproveitamento das biomassas renováveis (Esquema 1).

As biomassas oriundas de fontes renováveis e o carvão foram as matérias-primas utilizadas, na mesma proporção, pela humanidade até cerca de 100 anos atrás. A partir do início do século 20 o gás natural e o petróleo tornaram-se os principais componentes da matriz energética mundial, alcançando seu ápice no século 21, o que reduziu drasticamente o uso das biomassas renováveis e paralelamente foram crescendo os níveis de $\mathrm{CO}_{2}$ na atmosfera, devido à queima de gás e petróleo associado às devastações nas florestas.

O petróleo tornou-se a biomassa de origem fóssil mais importante e as previsões de que sua produção não seria reduzida antes de 2050 fizeram com que as indústrias químicas continuassem baseando seus processos nesta matéria-prima. Como consequência, uma parte substancial das necessidades energéticas do primeiro mundo mudou

*e-mail: cegvito@vm.uff.br

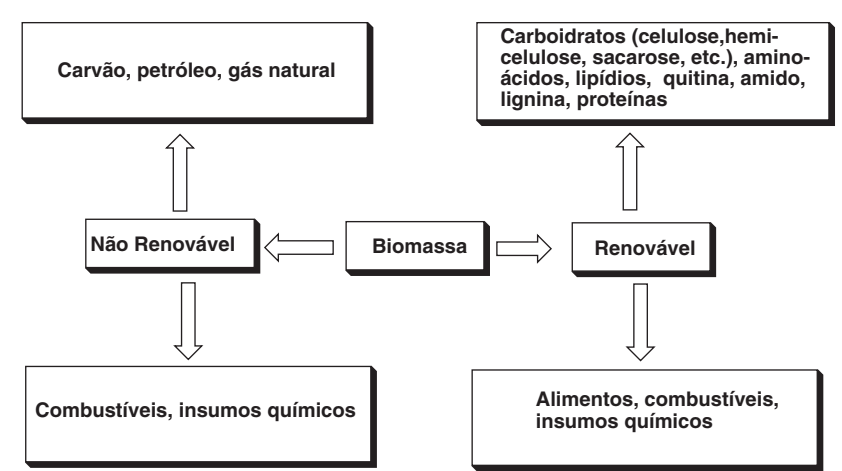

Esquema 1. Correlação entre as biomassas fósseis e renováveis

para esta nova indústria química orgânica,-agregando valor a uma percentagem do petróleo e tornando-o a base da indústria petroquímica. Assim, muitos dos seus derivados foram incluídos na saúde, alimentação, lar e outros produtos que temos hoje, principalmente plásticos e borrachas. Entretanto, ainda não existe uma previsão acurada da longevidade dos estoques do petróleo, mas seu preço no mercado internacional oscila bastante dependendo da conjuntura econômica mundial e dos países produtores. Atualmente as estimativas da longevidade das reservas estão entre 80-100 anos, porém, com as recentes descobertas de petróleo em águas profundas, nas camadas do pré-sal, essas previsões ficaram imprecisas.

Já existem processos químicos e biotecnológicos disponíveis para transformar certas biomassas em moléculas úteis, da mesma forma que a química orgânica fez com o petróleo no século passado. Ainda não são tão numerosos, contudo, é possível antecipar que neste século observaremos o crescimento das indústrias químicas baseadas em biomassas, paralelamente ao declínio da indústria petroquímica, o que ocorrerá com significativas vantagens ambientais. Diante desse cenário, o Brasil deveria desenvolver suas próprias tecnologias capazes de transformar suas biomassas renováveis e abundantes em intermediários de química fina ou insumos básicos para a indústria química, pois é fato que as matérias-primas fósseis se esgotarão. ${ }^{7}$ 
Independente do preço e da disponibilidade do petróleo e do gás natural, a queima de combustíveis fósseis é um fator que não pode (não deve) ser negligenciado por nenhum país, pois seu efeito no aquecimento global não é restrito. Neste cenário, é que as biomassas de fontes renováveis aparecem como alternativas economicamente atrativas para fixação de $\mathrm{CO}_{2}$, produção de biocombustíveis e insumos básicos para suprir as indústrias químicas. ${ }^{8}$

Além da questão econômica, a transição dos processos de preparação de insumos químicos a partir do petróleo para um sistema baseado em biomassas terá que transpor outros obstáculos, sendo o mais importante as diferenças químicas dos dois tipos de matériasprimas. As biomassas são compostas de substâncias mais complexas (carboidratos, aminoácidos, proteínas, lipídios e biopolímeros (polissacarídeos) ${ }^{9}$ como celulose, hemiceluloses, quitina, amido e lignina) que variam consideravelmente de massas moleculares (Esquema 2).

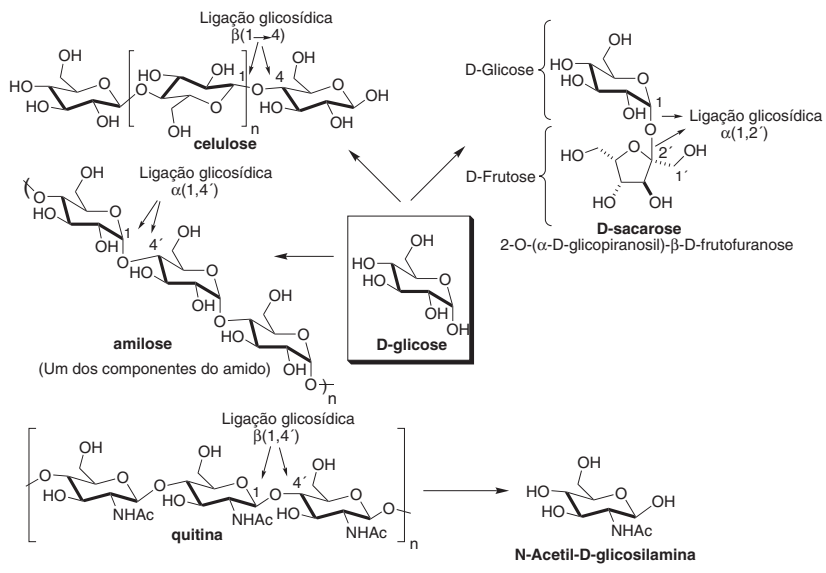

Esquema 2. As principais biomassas de renováveis baseadas em carboidratos

\section{CARBOIDRATOS}

Os carboidratos compõem $75 \%$ da biomassa da Terra representando a maior fonte renovável do planeta. Anualmente são convertidos mais de 100 bilhões de $\mathrm{m}^{3}$ de $\mathrm{CO}_{2}$ e $\mathrm{H}_{2} \mathrm{O}$ em 200 mil toneladas de carboidratos pelas plantas superiores e algas. ${ }^{10-12}$ Nesta classe, destacam-se a celulose, a hemicelulose, o amido e a sacarose, dentre outros carboidratos de massas moleculares menores. Estes carboidratos já são utilizados industrialmente em larga escala para diversos fins, mas alguns são utilizados principalmente para fins alimentares, tendo poucas aplicações nas indústrias químicas. ${ }^{13,14}$

Por serem materiais renováveis e de baixo custo, esses carboidratos deverão ser no futuro as fontes economicamente mais viáveis para substituir os atuais derivados petroquímicos. Em 1995 publicamos, nesta mesma revista, um artigo relatando a visão da época sobre o uso de carboidratos abundantes e suas aplicabilidades em síntese orgânica. ${ }^{15}$ Esta nova revisão pretende abordar, além do uso de carboidratos de baixas massas moleculares, as questões relativas às biomassas renováveis oriundas da fotossíntese e suas alternativas para a produção de intermediários e produtos da química fina.

Nestes últimos anos, muitas novas reações e materiais foram criados visando a produção de novos intermediários passíveis de uso pelos setores químicos da indústria, com a perspectiva que estes deveriam ser economicamente viáveis, para substituir aqueles derivados das fontes petroquímicas. Esta mudança baseia-se no fato das matérias-primas fósseis serem irrevogavelmente finitas, além da pressão gerada sobre o nosso meio ambiente com o aumento do $\mathrm{CO}_{2}$ oriundo da queima crescente de combustíveis fósseis. Com esta linha de atuação, as indústrias químicas vêem despertando seus interesses para fontes de matérias-primas limpas e renováveis, que possam manter o equilíbrio de $\mathrm{CO}_{2}$ no planeta. ${ }^{16}$

Os carboidratos existem difundidos em todos os seres vivos e são essenciais para a vida. ${ }^{17}$ Alguns existem praticamente puros, tais como a sacarose, o amido e a celulose, e este último no algodão, na madeira e no papel. Eles são os constituintes estruturais de tecidos de plantas (celulose), de alguns animais (quitina em crustáceos e insetos) e paredes de celulares de bactérias. Como novos açúcares biotransformados fazem parte das membranas celulares e do DNA e RNA, que carregam importantes informações genéticas nas células, glicoconjugados com uma variedade de produtos naturais, tais como antibióticos, glicolipídios, e glicoproteínas, sendo este dois últimos responsáveis por reter informações de reconhecimento supramolecular que formam a base da glicobiologia.

Apesar do papel principal dos carboidratos relacionado com suas diversas funções na bioquímica dos seres vivos, esta classe de substância tem sido largamente estudada pelos químicos orgânicos nos seus diversos aspectos estereoquímicos, mecanísticos, sintéticos e analíticos. A biomassa renovável de carboidratos é constituída principalmente de polissacarídeos como a celulose, o amido, a inulina e a hemicelulose que, por sua vez, são constituídos de unidades de menores massas moleculares. Para estes carboidratos utiliza-se o termo genérico monossacarídeo, indicando uma única unidade de açúcar sem conexões glicosídicas com outras unidades.

Os polissacarídeos podem ser utilizados in natura na alimentação, produtos têxteis, papel, madeira para construção, revestimentos industriais, cosméticos etc. Também podem sofrer modificações nas cadeias poliméricas de modo a adaptá-los para usos específicos, por exemplo, o rayon e a quitosana, obtidos respectivamente da celulose e a quitina, que mantêm as estruturas gerais dos polissacarídeos correspondentes. Em outro extremo têm-se as substâncias orgânicas classificadas como comodities e intermediários da química fina que têm baixas massas moleculares. É bem recente o interesse da indústria química nas fontes de matérias-primas renováveis, ${ }^{18}$ cujo desafio é transformar essa biomassa em carboidratos menores como dissacarídeos (celobiose) ou monossacarídeos (glicose, frutose, xilose) e este por sua vez nestas substâncias com maior valor agregado. ${ }^{19} \mathrm{Os}$ carboidratos de massas moleculares mais baixas apresentam maiores vantagens que os polissacarídeos para a preparação de insumos e intermediários da química fina, pois são de baixo custo e abundantes para usos em escala industrial (Esquema 3).

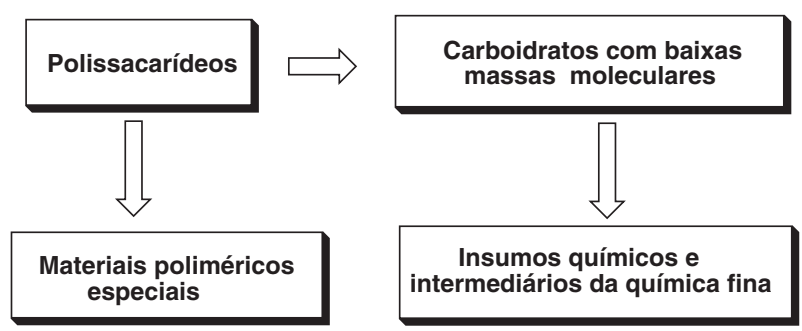

Esquema 3. Resumo esquemático das abordagens para os usos de polissacarídeos

\section{Celulose, amido, quitina e quitosana}

Os carboidratos podem possuir outras funcionalidades além dos grupos hidroxilas. Por exemplo, os amino-açúcares são carboidratos que possuem um grupo hidroxila substituído por uma amina. Os mais conhecidos destes carboidratos são os polissacarídeos quitina e quitosana ${ }^{20,21}$ (Figura 4) e o monossacarídeo D-glicosamina (2-amino2-desoxi-D-glicose). Uma excelente revisão sobre os derivados 
hidrossolúveis da quitosana e sua aplicações nas áreas farmacêuticas foi publicada recentemente por Silva e colaboradores. ${ }^{22}$

\section{Celulose}

A madeira é a principal fonte industrial de celulose. Ela é constituída principalmente pelos seguintes materiais lignocelulósicos: hemicelulose (20 a $25 \%$ ), celulose (40-50\%) e lignina (25 a 30\%), além de componentes inorgânicos (Esquema 4). Este conjunto de substâncias é responsável pelas propriedades mecânicas da madeira. As hemiceluloses são polissacarídeos ramificados com baixo grau de polimerização contendo uma mistura de polímeros de pentoses, como a D-xilose e a L-arabinose e, em menor quantidade as hexoses D-glicose, D-galactose, D-manose e ácidos glucurônicos. As hemiceluloses não são cristalinas e encontram-se intercaladas às microfibrilas da celulose dando elasticidade e impedindo que elas se toquem. As hemiceluloses variam nas estruturas e nas composições dependendo da fonte natural.

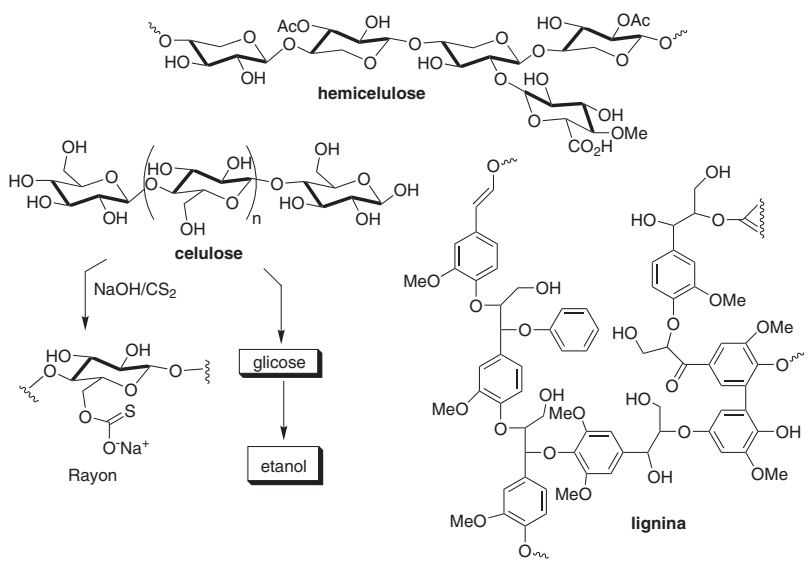

Esquema 4. Estruturas parciais dos componentes lignocelulósicos e derivados

A celulose é encontrada em plantas sob a forma de microfibrilas de 2 a $20 \mathrm{~nm}$ de diâmetro e entre 100 a $40.000 \mathrm{~nm}$ de comprimento, tendo entre 2.000-25.000 de resíduos de glicose. ${ }^{23}$ Estas microfibras estão em ligações lineares do tipo $\beta$ - $(1 \rightarrow 4)$ entre unidades de D-glucopiranose e na conformações ${ }^{4} \mathrm{C}_{1}$, onde formam agregados supramoleculares estruturalmente bastante resistentes e utilizados nas paredes celulares das plantas. ${ }^{24}$ Cada resíduo de glicose está orientado em $180^{\circ} \mathrm{em}$ relação ao próximo resíduo. As ligações de hidrogênio intramoleculares entre $\mathrm{O} 3-\mathrm{H} \rightarrow \mathrm{O} 5$ ', O6H $\rightarrow \mathrm{O} 2$ ' e O6 $\rightarrow \mathrm{HO} 3$ ' mantêm a rede mais fixa e com características hidrofóbicas. As interações de van der Waals entre as cadeias poliméricas formam zonas com estruturas cristalinas, em sua maioria, bastante ordenadas que não permitem a água penetrar no seu interior. ${ }^{25}$ Porém, outras zonas amorfas e secas podem absorver água e tornar a celulose macia e flexível. Estas ligações, juntamente com as zonas cristalinas, que alternam com zonas amorfas, correspondem a cerca de dois terços da celulose presente na madeira. Apesar da natureza higroscópica das moléculas individuais de celulose, a absorção de moléculas de água só é possível nas zonas amorfas devido à falta de espaços vazios na estrutura cristalina. A organização cristalina da celulose influencia a sua reatividade ao controlar o acesso de substâncias químicas ou enzimas aos grupos funcionais e às ligações químicas nas regiões cristalinas. As hidroxilas são os grupos mais abundantes na celulose, seguidos pelas ligações acetal que formam o anel das piranoses. ${ }^{26}$

Cada espécie de árvore possui fibras de celulose de diferentes morfologias. Devido a isso, esse polissacarídeo tem muitas utili- zações na fabricação de diversos tipos de papel, e também como agente antiaglutinante (anticaking agent), emulsificante, estabilizante, dispersante, espessante, indutor de gelatinização, entre outros, pois em contato com a água pode aumentar o volume e a textura, especialmente em cosméticos. A celulose pode ser modificada nas suas hidroxilas e produzir matéria com propriedades importantes (ex. triacetato de celulose, nitrocelulose, carboximetil celulose e rayon). O rayon ou viscose é uma fibra celulósica semissintética modificada na hidroxila primária. Esta pequena modificação confere um aspecto sedoso e brilhante na fibra celulósica.

No Brasil, a celulose é produzida em grande escala a partir do eucalipto por diversas empresas (ex. Aracruz, Jari, Suzano e Votorantin) e em 2004 contava com 220 empresas localizadas em 16 estados e 450 municípios, gerando 100.000 empregos, o que torna o país o maior produtor mundial de celulose de eucalipto. ${ }^{27,28}$ Esta espécie utilizada tem o dobro da produtividade de outras coníferas plantadas no Brasil e da maioria das árvores nativas.

\section{Hemiceluloses}

As hemiceluloses são polissacarídeos que representam um dos componentes da parede celular vegetal e estão intimamente associadas à celulose, definindo as propriedades estruturais na parede celular além de desempenhar funções na regulação do crescimento e desenvolvimento das plantas. Os xiloglucanos (Xg) e os galactomananos são hemiceluloses presentes tanto em parede primária (função estrutural) como em parede de reserva em sementes de algumas espécies (função de reserva). Os resultados mostraram que o grau de ramificação e o tamanho da cadeia afetam a interação entre $\mathrm{Xg}$ e a celulose. Enquanto os graus de galactosilação e fucosilação estão relacionados com a força de ligação entre os polissacarídeos, o tamanho da molécula do Xg afeta a sua capacidade (quantidade) de interação à celulose, consequentemente a autointeração.

\section{Amido}

É o segundo polissacarídeo mais abundante. Pode ser encontrado em sementes, raízes e fibras de plantas. É a fonte de energia, em termos de glicose, mais abundante para os humanos. Ele é composto basicamente de dois polissacarídeos de D-glicose: amilose e amilopectina. A diferença entre estes dois polímeros está no encadeamento das unidades glicosídicas. Na amilose a cadeia é linear e as ligações são $\alpha-\left(1 \rightarrow 4^{\prime}\right)$. Na amilopectina há uma ramificação na hidroxila de C6 com uma ligação $\alpha-\left(1 \rightarrow 6^{\prime}\right)$. Porém, as ligações $\alpha-\left(1 \rightarrow 4^{\prime}\right)$ continuam no polímero. A sua composição varia de acordo com a planta. Por exemplo, o amido da batata difere basicamente do amido do aipim (macaxeira) na relação entre amilose e amilopectina. A maioria dos seres vivos pode utilizar estes polissacarídeos como fonte energética, pois possuem enzimas $\alpha$-amilases na saliva e no intestino que quebram a ligação $\alpha-\left(1 \rightarrow 4^{\prime}\right)$ entre as unidade de glicose. O mesmo não acontece com a celulose. A maioria dos animais não consegue utilizá-la como alimento. A razão está na ligação $\beta-(1 \rightarrow 4$ ') que não está presente nos animais superiores. Entretanto, cupins conseguem digerir a celulose facilmente, pois têm no seu intestino bactérias simbióticas que secretam a enzima celulase que faz a hidrólise da ligação $\beta$ - $(1 \rightarrow 4$ '). Alguns vertebrados herbívoros também conseguem fazer a digestão, pois têm bactérias no estômago que secretam celulase.

Na conformação $\alpha-\left(1 \rightarrow 4^{\prime}\right)$, mais estável nos polissacarídeos amilose, amilopectina e glicogênio, as cadeiras ficam rígidas tornando a cadeia curva ao invés de linear, como na celulose. Este arranjo produz estruturas compactas e helicoidais produzindo grânulos densos que podem ser visualizados em muitas células.

O glicogênio é o principal polissacarídeo de estocagem de energia 
das células. Como na amilopectina, o glicogênio é um homopolímero da D-glicose com ligações $\alpha-\left(1 \rightarrow 4^{\prime}\right)$ com ramificações $\alpha-\left(1 \rightarrow 6^{\prime}\right)$, mas com um número maior de ramificações (uma ramificação por 8 a 12 resíduos de glicose). Estas ramificações tornam o glicogênio mais compacto que o amido. Ele é disseminado nos músculos, mas é especialmente abundante no fígado, onde chega a ter $7 \%$ do peso deste órgão.

\section{Quitina e quitosana}

A D-glicosamina acetilada é o constituinte da quitina que é o principal componente estrutural (exo-esqueleto) de milhares de insetos (cigarras, baratas etc) e crustáceos (siri, camarão etc), mas também aparece em mamíferos nas glicoproteínas. No reino vegetal ela é mais escassa e só ocorre em fungos e algas verdes. Em realidade, a quitina e a quitosana (parcialmente desacetilada) são copolímeros constituídos por unidades D-glicosamina e N-acetil-D-glicosamina em proporções variáveis, sendo que na quitina se tem maior proporção de N-acetil-D-glicosamina.

A quitina é dos polissacarídeos mais abundantes na natureza constituído de unidades $\mathrm{N}$-acetil- $\beta$-D-glicosamina com ligações glicosídicas $\beta-(1 \rightarrow 4)$ formando fibras estendidas. ${ }^{29}$ Comparando a sua estrutura com a da celulose observa-se a mesma distribuição e arranjos espaciais dos anéis pirânicos, porém o grupo hidroxila do C-2 foi substituído por um grupo $\mathrm{N}$-acetilamino. A quitina também não é digerida pelos animais vertebrados devido à ligação $\beta-(1 \rightarrow 4)$. Duas importantes substâncias podem ser obtidas a partir da quitina e que apresentam um enorme potencial econômico: o hidrocloreto da D-glicosamina, que pode ser obtido facilmente da quitina de casca de camarão ou conchas de mariscos por hidrólise ácida $(\mathrm{HCl}$ concentrado ou $\left.\mathrm{H}_{2} \mathrm{SO}_{4}\right)^{30}$ e, quitosana (Esquema 5). Neste aspecto, considera-se este polissacarídeo como sendo uma excelente fonte de biomassa renovável com boas perspectivas de desenvolvimento de novos intermediários químicos e produtos de maior valor agregado.

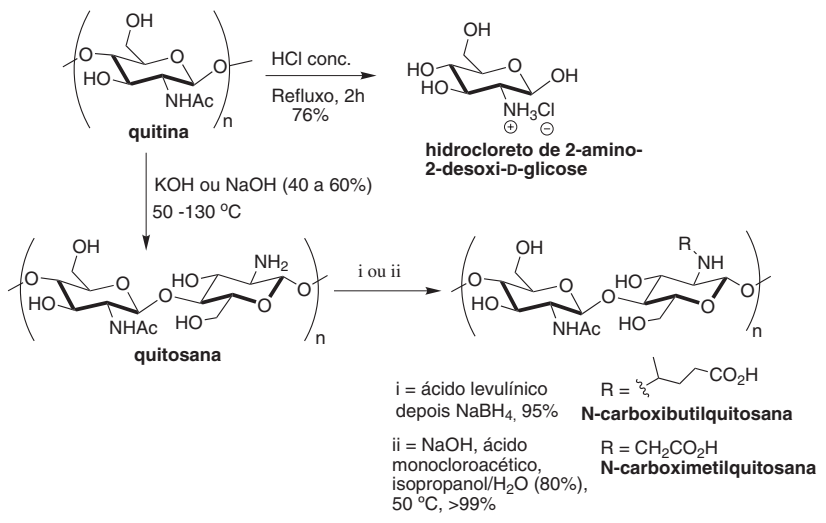

Esquema 5. Produtos derivado da quitina

A quitosana é um polímero parcialmente desacetilado derivado da quitina (Esquema 5), podendo ser obtido por hidrólise do grupo acetila com $\mathrm{KOH}$ ou $\mathrm{NaOH} .{ }^{31}$ Para se obter a quitosana diretamente da casca do siri ou camarão são necessárias três etapas: descalcificação com $\mathrm{HCl}$ diluído, desacetilação com solução de $\mathrm{NaOH}$ e descoloração com solução de $\mathrm{KMnO}_{4}$ e ácido oxálico. As suas propriedades físicoquímicas dependem do grau de desacetilação, podendo ter utilizações específicas. A solubilidade em água, viscosidade e o pKa dependem diretamente do número médio de hidroxilas livres.

A quitosana é um produto comercialmente disponível e produzido no Brasil, sob a forma de copolímeros que contém ao menos 40-50\% de unidades de 2-acetamido-2-desoxi-D-glicopiranose, e que são solúveis em soluções aquosas diluídas de ácidos. São múltiplas as suas utilizações nas indústrias farmacêuticas em medicamentos, cosméticos, biomateriais, géis, filmes e membranas poliméricas. O desenvolvimento de novas aplicações para este biopolímero é economicamente muito atrativo, pois é obtido de fontes renováveis, ou subproduto destas (ex. casca de camarão), além da sua biodegradabilidade e biocompatibilidade, principalmente sua atoxidez e capacidade de interagir com diversas substâncias.

É importante ressaltar as diversidades de atividades biológicas e fisiológicas destes dois polissacarídeos quando comparadas com outros polissacarídeos similares (ex. celulose e amido). A quitina e a quitosana têm moderada ação antimicrobiana provavelmente devido à presença dos grupos amino que podem causar aglutinação das células dos micro-organismos. ${ }^{32}$ Ademais, apresentam propriedades imunomoduladora e, consequentemente, promotoras da aceleração da cicatrização de lesões, principalmente devido à capacidade de ativação seletiva de macrófagos. ${ }^{33}$ Há alguns outros usos específicos da quitosana que devem ser destacados, como tratamento da obesidade e excesso de colesterol, removedor de metais, floculante, coagulante, bandagens médicas, queimadura de pele, lentes de contato, umectante para cosméticos, tratamento de papel, papel fotográfico, membranas para osmose reversa, controle de liberação de agroquímicos, cromatografia, estabilizante de cor etc. ${ }^{34}$

Não menos importantes são os derivados da quitosana substituídos no grupo amino livre que visam a modificação de diversas propriedades físico-químicas destes materiais, ${ }^{35,36}$ sendo a mais importante a solubilidade em água. Diversos trabalhos publicados relatam que derivados hidrofílicos podem ser obtidos com o substituinte carboxibutila. ${ }^{37,38}$ Então, a condensação da quitosana com o ácido levulínico ${ }^{38}$ ou cloroacético ${ }^{39} \mathrm{em}$ diferentes condições reacionais favorece a formação da $\mathrm{N}$-carboxialquilquitosana com grau de substituição variável dependendo da metodologia. ${ }^{34,40}$

\section{Principais dissacarídeos}

Assim como os polissacarídeos citados anteriormente, os dissacarídeos destacam-se também como importantes fontes de biomassas renováveis, destacando-se a D-sacarose, celobiose, lactose e a maltose (Esquema 6).
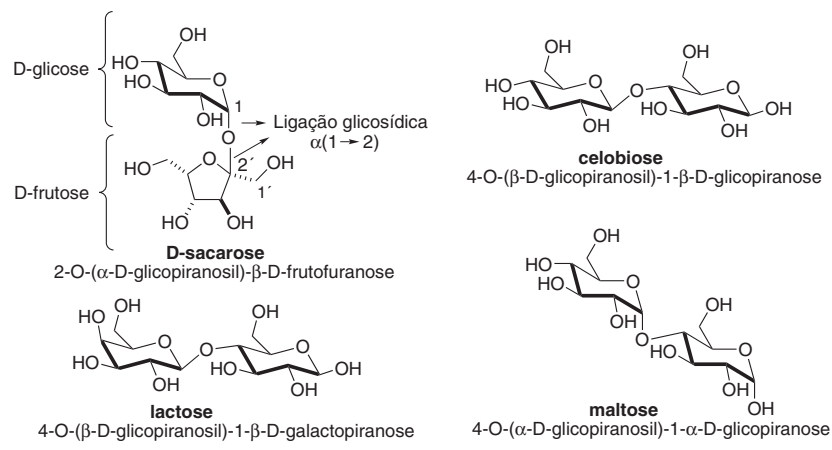

Esquema 6. Dissacarídeos importantes na biomassa terrestre

\section{Sacarose}

A sacarose, uma substância conhecida desde o ano 200 a.C., ${ }^{41,42}$ é o carboidrato de baixa massa molecular mais abundante. É produzido em larga escala por diversos países, principalmente para usos alimentares, pois é um alimento natural e amplamente utilizado como ingrediente. É um dissacarídeo não redutor constituído de dois monossacarídeos, D-glicose e D-frutose, que estão ligados entre si através dos seus carbonos anoméricos. É conhecido genericamente 
com o nome de açúcar e está distribuído em todo o reino vegetal, sendo o principal carboidrato de reserva de energia e material indispensável para a dieta humana. Durante séculos, foi o mais abundante composto orgânico produzido de baixa massa molecular. É a substância orgânica cristalina de maior produção mundial tendo duas fontes naturais importantes: beterraba (Beta vulgaris) e canade-açúcar (Sacharum officinarum), esta última é cultivada em 103 países sendo responsável por $60-70 \%$ da sua produção. ${ }^{43} \mathrm{~A}$ indústria da cana-de-açúcar tem algumas vantagens, pois não utiliza reagentes tóxicos ou perigosos. É importante ressaltar que a cana-de-açúcar tem um dos mais eficientes mecanismos fotossintéticos para a produção de biomassa que lhe permite fixar entre 2 e $3 \%$ da radiação solar. O processo de produção de açúcar é autossuficiente em energia, pois o bagaço obtido como subproduto incluindo celulose, hemicelulose e lignina (baixa massa molecular) é utilizado como combustível nas usinas, representando uma economia significativa no uso do petróleo. $\mathrm{O}$ grande desafio atual é transformar este bagaço em produtos economicamente mais atrativos como, por exemplo, o etanol e assim aumentar sua produção.

A sacarose e a glicose são os principais carboidratos de baixas massas moleculares para a síntese orgânica. Não existe um levantamento confiável do número de processos que foram relatados na literatura a partir da sacarose como matéria-prima, porém há cerca de 100 processos tecnicamente viáveis que estão sendo utilizados em escala comercial. O seu uso como reagente químico tem basicamente três grandes estratégias. A mais comum é a transformação radical da sua estrutura por meio de processos químicos ou fermentativos (biotecnologia). ${ }^{44}$ Nesta linha, muitos produtos foram obtidos em escala industrial sendo o mais conhecido e de maior escala o etanol. ${ }^{45}$ Este álcool é a principal entrada da sacarose na indústria de derivados similares aos obtidos pela indústria petroquímica (exemplo eteno, acetaldeído, acetato de etila, anidrido acético, butanol etc). Outras possibilidades são a manutenção da estrutura carbônica com modificações nas hidroxilas ou isomerização da ligação glicosídica (Esquema 7).

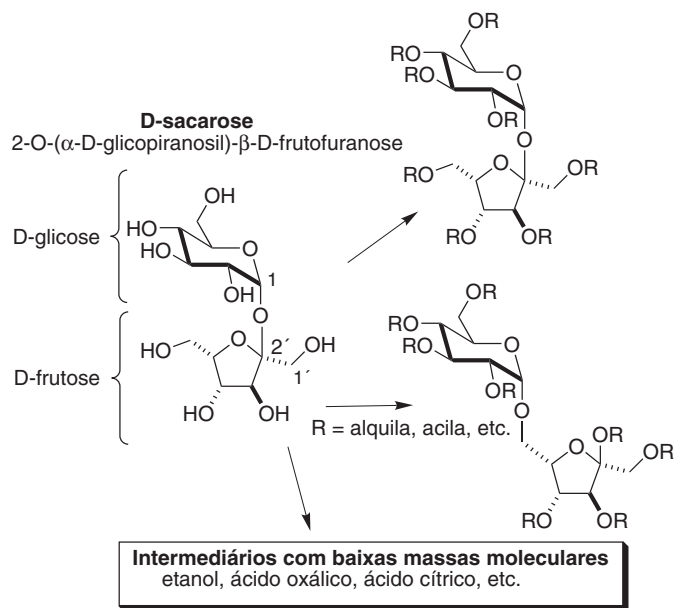

Esquema 7. Estratégias para o uso da D-sacarose como reagente químico

A produção mundial de sacarose entre 2007/2008 foi de cerca de 168 milhões de toneladas ${ }^{46}$ e continua com perspectivas de crescimento. Em abril de 2008 o preço médio atingiu, no mercado dos EUA, o valor de US\$29,10/t, aproximadamente $29 \%$ mais elevado do que o mesmo mês no ano de 2007. No Brasil estima-se a produção em 34,1 milhões de toneladas (2007/08), representando 6,6\% ou 2 milhões de toneladas, mais do que em 2006/07. As condições atmosféricas favoráveis e as elevadas taxas de extração de açúcar impulsionaram a produção.
A introdução dos veículos que funcionam com misturas flexíveis etanol-gasolina impulsionou a produção de etanol com preços mais vantajosos para o consumidor. Estima-se que 56\% da produção da sacarose serão transformados em etanol. É importante ressaltar que o modelo de produção do etanol a partir da cana-de-açúcar não pode ser aplicado a todos os países, principalmente aqueles que têm severas restrições aos recursos hídricos.

A demanda por etanol está se tornando uma componente fundamental do mercado de açúcar nacional e, portanto, ampliar sua produção, sem ampliar a área plantada é um dos desafios tecnológicos para os próximos anos. Para tanto, são necessárias novas tecnologias que transformem o bagaço e as folhas da cana em etanol (combustível de segunda geração), ${ }^{47}$ deixando a sacarose como um produto mais nobre para a alimentação e para a produção de outros derivados de maiores valores agregados. A primeira geração de etanol tem tecnologias bem estabelecidas para algumas culturas, mas o desenvolvimento de processos relacionados à sua produção de segunda geração utilizando a biomassa de madeira está ainda nas fases iniciais da investigação e desenvolvimento.

Há muitos anos o estudo da sacarose como matéria-prima para a produção de insumos para a indústria química e a produção de novos derivados com maior valor agregado tem despertado o interesse dos pesquisadores e de políticas específicas para este setor. Esse ramo da química é tão importante que passou a ser conhecido como sucroquímica, que é entendida como o ramo da ciência e da tecnologia cujo objetivo é acrescentar ao mercado novas utilizações da sacarose e seus derivados, seja por processos de transformações radicais na estrutura carbônica ou por processos que envolvem modificações nas hidroxilas, conforme resumidas no Esquema $8{ }^{48}$ No Brasil ficaram conhecidas as iniciativas de projetos de pesquisa em sucroquímica no Rio de Janeiro ${ }^{49}$ e Pernambuco. ${ }^{50}$

Historicamente a sacarose foi considerada inicialmente como alimento, e muito posteriormente como um poli-álcool pelos quími$\cos$. Esses fatos ofuscaram durante muitos anos sua utilização como matéria-prima para a indústria química. As duas crises do petróleo, em meados de 1970 e início de 1980, levaram os pesquisadores à procura de novas fontes de produtos químicos derivados de fontes renováveis que podem ser produzidos em escala industrial. Então, matérias-primas como a sacarose tornaram-se de grande interesse econômico. ${ }^{51}$

Comparativamente, o baixo custo, a disponibilidade e a pureza fazem com que esta matéria-prima, ou alguns de seus derivados, seja extensivamente vantajosa para novos processos industriais. A sua maior desvantagem é a fragilidade da ligação glicosídica $\alpha-(1 \rightarrow 2)$. Realmente, esta ligação é extremamente sensível a condições ácidas. Outra desvantagem apontada por alguns autores é sua superfuncionalidade, ou seja, um excessivo número de hidroxilas (oito) com reatividades similares. Entretanto, existem pequenas diferenças de reatividades entre as hidroxilas primárias e secundárias que têm sido exploradas em reações de acetilação, halogenação, dentre outras. ${ }^{52}$ Apesar dessas desvantagens, sugeridas por alguns autores, muitos produtos monossubstituídos e polissubstituídos encontram-se no mercado (ex. ésteres graxos da sacarose).$^{53}$

Focalizando a linha de transformações radicais na estrutura carbônica da sacarose, o Esquema 8 apresenta um resumo de alguns produtos químicos de baixa massa molecular que são obtidos em escala industrial por processos químicos ou fermentativos (aeróbicos e anaeróbicos). Estas substâncias podem servir de matérias-primas para a síntese de outros produtos mais elaborados. É importante ressaltar que muitos destes intermediários também podem ser obtidos a partir da glicose que, por sua vez, pode ser obtida do amido ou da celulose. Outra matéria-prima para a obtenção destes produtos é o açúcar invertido, mistura equimolecular de glicose e frutose, obtida por hidrólise 
da sacarose. A alternativa no uso de biomassas torna mais atrativa as rotas de obtenção destes produtos a partir de carboidratos, pois nem todos os países produzem sacarose. Na Tabela 1 estão detalhados os tipos de rotas para a obtenção destes intermediários e um breve resumo de suas possíveis aplicações.

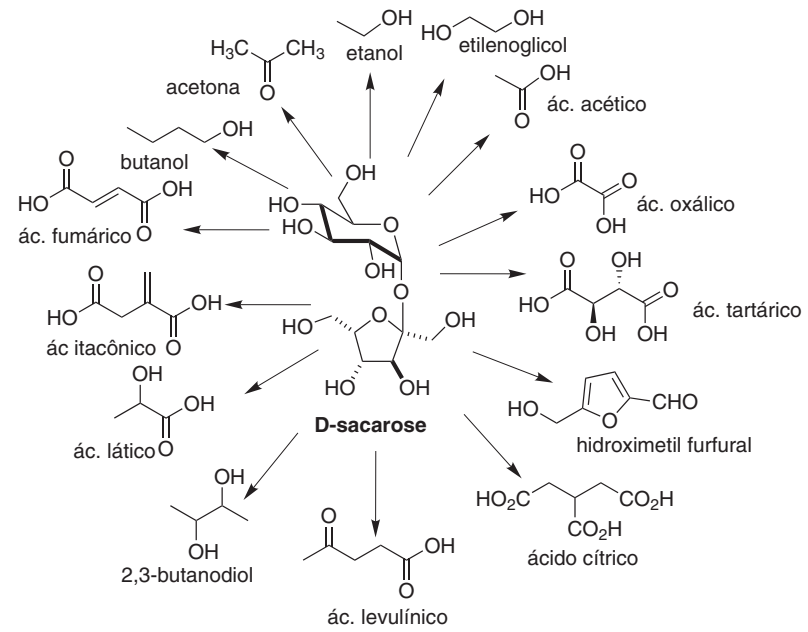

Esquema 8. Alguns produtos químicos com baixas massas moleculares obtidos a partir da sacarose
Ésteres graxos da sacarose

Dos derivados mencionados acima, os ésteres de sacarose ou sucroésteres são os mais importantes devido as suas múltiplas aplicações tecnológicas e, consequentemente, as grandes possibilidades de usos comerciais. Estes ésteres são obtidos por reação de esterificação direta $^{76}$ ou transesterificação. ${ }^{77}$ Os ésteres graxos da sacarose são muito úteis e podem ser obtidos por esterificação direta com cloretos de ácidos ou anidridos ou transesterificação a partir de triglicerídeos (lipídios) que representam outro tipo de biomassa abundante. Como os ésteres derivados de ácidos graxos contêm dois componentes naturais, esperar-se-ia que pudessem ser utilizados como alimentos. Entretanto, há controvérsias especialmente para o caso dos ésteres com alto grau de substituição. Os ésteres de sacarose têm boa aceitação em formulações cosméticas às suas propriedades emulsificantes e à sua inocuidade dermatológica. Da mesma maneira, eles têm sido utilizados em detergentes biodegradáveis, para diversos usos como, por exemplo, na extração de petróleo derramado no mar.

Suas características físico-químicas dependem do grau de substituição, além do tamanho e número de insaturações das cadeias, das hidroxilas da sacarose que se traduz através do balanço entre a hidrofilicidade e a lipofilicidade. Sendo assim, é possível conseguir uma grande variação nas características emulsificantes dos ésteres graxos da sacarose, como no caso dos monoésteres com cadeias C16-18 que, praticamente insolúveis em água, se comportam como surfactantes não-iônicos. ${ }^{78}$

Tabela 1. Substâncias obtidas a partir da sacarose por via química ou fermentativa

\begin{tabular}{|c|c|c|}
\hline SUBSTÂNCIA & PROCESSO & PRINCIPAL USO \\
\hline Ácido Oxálico & Químico & Decapagem, fotografia, clareamentos. ${ }^{54}$ \\
\hline Ácido Acrílico & Químico & Polímeros, materiais têxteis, adesivos, etc. ${ }^{55}$ \\
\hline Ácido Acético & Bioquímico - Clostridum termoaceticum & Solvente industrial, cosméticos, alimentação $0^{56}$ \\
\hline Ácido Cítrico & Bioquímico - Aspergillus niger & Acidulante \\
\hline $\begin{array}{l}\text { Ácido Itacónico ou ácido } \\
\text { metileno succínico }\end{array}$ & Bioquímico - Aspergillus terreus & $\begin{array}{l}\text { Aglutinante para plásticos, colas, tintas, lubrificantes e } \\
\text { revestimentos }{ }^{57,58}\end{array}$ \\
\hline Ácido Lático & Bioquímico - Lactobacillus delbrueckii & Intermediário $^{59}$ \\
\hline Ácido L-Glutâmico & Bioquímico - Micrococcus glutamicus & Usos em alimentos ${ }^{60}$ \\
\hline Ácido Tartárico & $\begin{array}{l}\text { Químico e Bioquímico } \\
\text { Gluconobacter suboxydans }\end{array}$ & Flavorizante, fotografia, bebidas, ligante quiral ${ }^{61,62}$ \\
\hline Ácido Propiónico & Bioquímico - Rhizopus nigricans & Intermediário \\
\hline Açúcar Invertido & Químico ou Bioquímico & Alimentos ${ }^{63,64}$ \\
\hline Poliacrilato & Químico & Encapsulamentos e hidrogel ${ }^{65}$ \\
\hline n-Butanol & Bioquímico - Clostridium acetobutylicum & Solvente ${ }^{66}$ \\
\hline Dextranas $^{67}$ & Bioquímico - Leuconostoc mesenteroides & Cromatografia, Emulsificante, Petróleo ${ }^{68}$ \\
\hline Etanol $\rightarrow$ Eteno & Bioquímico (Saccharomyces cerevisiae) e Químico & Combustível e polímeros ${ }^{45,47}$ \\
\hline Ésteres Graxos & Químico & De tensoativo atóxico à substituto de gordura ${ }^{53}$ \\
\hline $\begin{array}{l}\text { Ésteres misto de acetato } \\
\text { isobutirato (SAIB) }\end{array}$ & Químico & Emulsões em bebidas, cosméticos, fixador ${ }^{69}$ \\
\hline Epóxi Ésteres & Químico & $\operatorname{Resinas}^{70,71}$ \\
\hline Gomas Xantânicas & Bioquímico - Xanthomonas campestris & Cosméticos \\
\hline Hidrogéis & Químico/Bioquímico & Absorvente $^{72}$ \\
\hline Poli-acetatos & Químico & Adesivos e Vernizes ${ }^{73}$ \\
\hline Sucralose & Químico & Adoçante Artificial ${ }^{74}$ \\
\hline Uretanos & Químico & Polímeros ${ }^{75}$ \\
\hline
\end{tabular}


Em termos de atividades farmacológicas, alguns destes ésteres mostraram atividade inseticida contra a formiga Atta sexdens. ${ }^{79}$ Dependendo do tamanho da cadeia, os ésteres graxos mono, di e trissubstituídos da sacarose são pouco hidrolisados pelas lipases intestinais, logo, muito pouco absorvidos pelo organismo e as bactérias intestinais.

Dentre os poliésteres de ácidos graxos o produto comercial Olestra (Procter \& Gamble Co) ou Olean ${ }^{\circledR}$ (Twin Rivers Technologies) tem recebido atenção especial nos últimos anos devido à sua utilização em dietas hipocalóricas e como depressor do nível de colesterol sanguíneo (Esquema 9). Este poliéster graxo da sacarose com grau de esterificação superior a seis foi aprovado pelo FDA em 1996 para consumo humano. Ele apresenta propriedades físico-químicas semelhantes às dos triglicerídeos naturais (gorduras naturais), sendo atualmente utilizado como substituto não calórico de gorduras na fabricação de produtos alimentícios como batatas fritas, biscoitos, pipocas etc. Entretanto, há um intenso debate sobre a ação deste de substituto de gordura em alimentos de baixa caloria. Na realidade ainda não está absolutamente provado que este substituto de gordura tem segurança para uma nutrição saudável, pois muitos estudos mostraram que causa problemas estomacais e perda de vitamina D. Em 2002 a Procter \& Gamble Co. introduziu uma família de poliésteres ésteres graxos da sacarose não-tóxicos e, com base em matériasprimas renováveis, denominada de $\mathrm{SEFOSE}^{\circledR}$ (SEFOSE-1618S, SEFOSE-1618H e SEFOSE-2275), com vasto leque de propriedades de desempenho em uma variedade de aplicações. São hexa, hepta e octaésteres da sacarose com um mínimo de $70 \%$, em peso, do octaéster. São bons lubrificantes para muitas aplicações industriais (fluidos para torneamento de metais, lubrificante têxtil etc.) porque mantêm alto desempenho sem contaminar o meio ambiente.

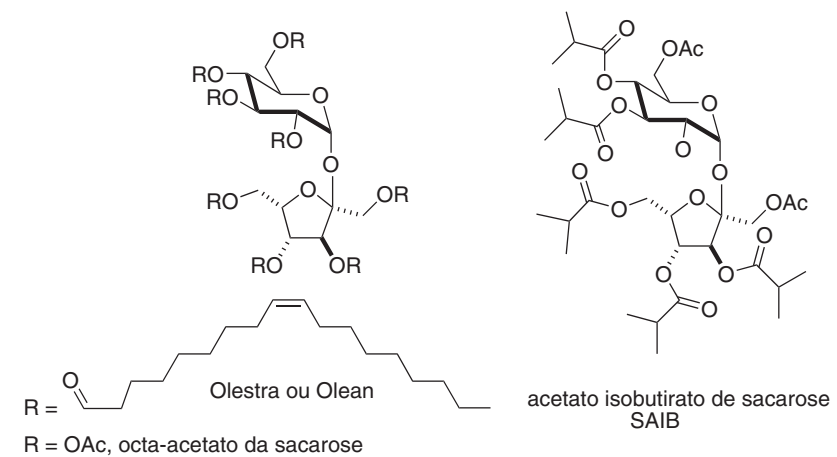

Esquema 9. Poliésteres da sacarose com expressiva produção industrial

O acetato - isobutirato da sacarose (SAIB ou Sustane, Esquema 9) é um aditivo alimentar utilizado como estabilizador em emulsões aroma em refrigerantes (emulsificante E444), fixador de fragrâncias, umectante de baton, tinturas para cabelos etc. Ele tem sido utilizado por mais de 30 anos em muitos países em bebidas não alcoólicas gaseificadas e não carbonatadas. Estudos realizados para esta substância não detectaram sinais de toxicidade. ${ }^{80,81}$

Outros sucroésteres interessantes que merecem destaque são os sucrogéis.$^{82}$ Estas substâncias pertencem à família dos hidrogéis, que são materiais poliméricos caracterizados pela alta hidrofilicidade, insolubilidade em água, biocompatibilidade e biodegradabilidade. ${ }^{83}$ A hidrofilicidade é devido à presença de grupos hidroxilas que se ligam com moléculas de água criando, desse modo, uma estrutura de gel. Mais recentemente os hidrogéis têm sido associados com argilas de características lamelares que aumentam seus poderes de absorção de água. ${ }^{84,85}$

Os sucrogéis superabsorventes são polímeros hidrofílicos ligados que possuem ligações cruzadas, lineares ou ramificadas com a habilidade de absorverem grandes quantidades de água, soluções salinas e fisiológicas. São de grande utilização na fabricação de muitos materiais, como fraldas, absorventes femininos, no solo para a agricultura e horticultura e na medicina, ${ }^{86} \mathrm{em}$ suturas cirúrgicas e em sistemas de liberação controlada de fármacos. ${ }^{87,88}$ Para a preparação dos monômeros, que são utilizados na produção de polímeros contendo a sacarose, há necessidade de proteção das hidroxilas por via química ou bioquímica e posteriormente incorporação de uma unidade polimerizável. No Esquema 10 estão mostrados ésteres acrílicos e metacrílicos. Todos quando polimerizados de forma cruzado com outros monômeros fornecem polímeros que absorvem grande quantidade de água.
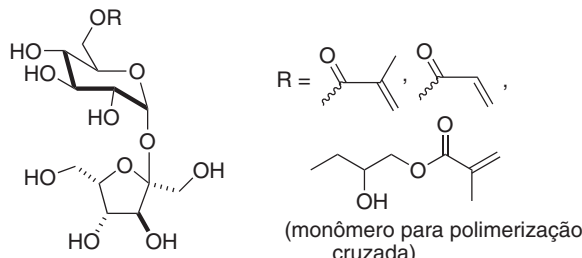

Esquema 10. Monoésteres da sacarose utilizados na preparação de hidrogéis

\section{Éteres da Sacarose}

Os éteres derivados da sacarose são obtidos através da substituição de átomo de hidrogênio da hidroxila por grupos alquila ou benzila. Algumas propriedades dos compostos resultantes são atraentes de um ponto de vista comercial, mas limitado aos uretanos. Entretanto, os derivados octa-alil e octacrotilsacarose são bastante interessantes para a produção de novos materiais poliméricos. Estes éteres derivados da sacarose, assim como o alil amido e a alil celulose, são conhecidos desde a década de $40 .{ }^{89}$ Eles oferecem boas potencialidades e custo baixo para a preparação de novos materiais. Um dos materiais poliméricos mais conhecidos da octa-alilsacarose é o carbopol, um polímero cruzado com poliacrílico. São amplamente utilizados nas indústrias farmacêutica e cosmética para espessamento de suspensão e substâncias insolúveis, estabilizador de emulsões, pastas, pomadas, geléias etc. e têm excelente estabilidade térmica e resistência microbiana para fungos (Esquema 11).
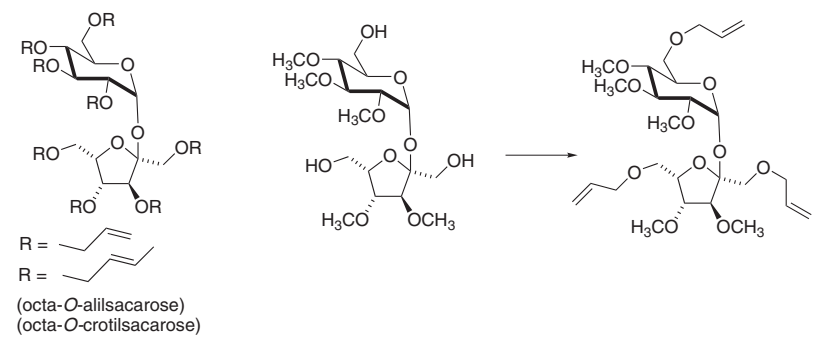

(octa-O-alilsacarose)

Esquema 11. Exemplos de éteres da sacarose utilizados em preparações poliméricas

\section{Sucralose}

Algumas hidroxilas da sacarose podem ser substituídas por cloro. É bem conhecido que as hidroxilas primárias 6 e $6^{\prime}$ são facilmente substituídas pela sua reação com trifenilfosfina em tetracloreto de carbono em bom rendimento. Este derivado diclorado ainda não foi bem aproveitado, tendo em vista que o método da sua produção não é o mais recomendado. Já o derivado triclorado nas posições 4 , $1^{\prime}$ e $6{ }^{\prime},{ }^{90}$ conhecido no mercado pelos nomes sucralose ou Splenda ${ }^{\circledR}$ 
(4,1',6'-tricloro- 4,1',6'-trideoxigalactofrutose), é 600 vezes mais doce que a sacarose, não calórico, anticariogênico e estável em temperaturas de cozimento de alimentos. ${ }^{91,92}$ Esta substância foi liberada pelos órgãos de vigilância sanitária sendo comercializada, inclusive no Brasil, como adoçante não calórico.
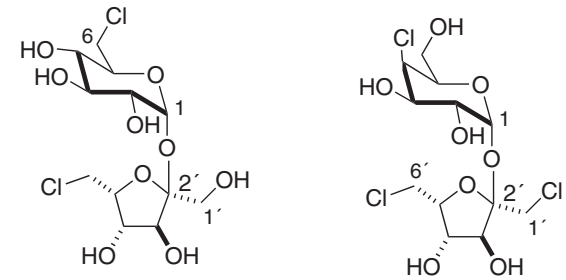

(6,6'-dicloro-6,6'-didesoxiglico-frutose)

Sucralose

Esquema 12. Exemplos de derivados da sacarose seletivamente substituídos por cloro

\section{Isomaltulose e leucrose}

Anteriormente foi mostrado que a sacarose pode servir de matériaprima para a produção de diversos intermediários de baixas massas moleculares por via química ou bioquímica. Alternativamente, é possível a manutenção da estrutura carbônica transformando-a em outros dissacarídeos isoméricos como D-glicosil-D-frutoses. Os cinco possíveis isômeros são trivialmente designados como trealulose, turanose, maltulose, leucrose e isomaltulose. Dois destes dissacarídeos têm grande potencial de aplicabilidade industrial e já são produzidos industrialmente: isomaltulose e leucrose (Esquema 13).

A isomaltulose é um dissacarídeo comercialmente conhecido como Palatinose $^{\circledR}$ ou Lylose ${ }^{\circledR}$. Este carboidrato é um isômero de posição da sacarose sendo encontrado em pequenas quantidades no mel e no caldo de cana-de-açúcar. É produzido por processo fermentativo utilizando diversos micro-organismos produtores da enzima glicosiltransferase que convertem a sacarose $\alpha-\left(1 \rightarrow 2^{\prime}\right)$ para seu isômero $\alpha-\left(1 \rightarrow 6^{\prime}\right)$. Esta enzima não é comercializada, porém existem diversos micro-organismos que a possuem e são capazes de fazer a isomerização de sacarose para isomaltulose. ${ }^{93} \mathrm{O}$ micro-organismo mais utilizado industrialmente para sua produção é a proteobactéria Protaminobacter rubrum ${ }^{94,95}$ tendo uma produção mundial crescente, encontrando-se atualmente na faixa de $60.000 \mathrm{t} /$ ano. ${ }^{12}$ Este dissacarídeo é utilizado como adoçante alternativo, pois é pouco calórico e tem baixo potencial cariogênico. ${ }^{96}$ É menos doce do que sacarose (cerca de 50\%), mas pode ser consumido por pessoas com diabetis. ${ }^{97,98} \mathrm{O}$ seu sabor, aparência e viscosidade de soluções aquosas são semelhantes aos da sacarose. Duas propriedades são muito importantes na isomaltulose: maior estabilidade sob condições ácidas, não sendo facilmente hidrolisada e, é fermentada em taxas mais baixas quando comparada com açúcares como a sacarose ou maltose por micro-organismos intestinais. Após a absorção, a glicose e a frutose de ambos são metabolizadas seguindo as mesmas rotas bioquímicas clássicas. Como a sua hidrólise é mais lenta, ela é uma fonte energética mais constante para bebidas e alimentos visando o

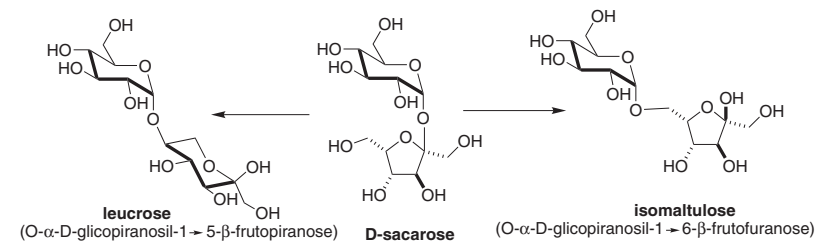

Esquema 13. Dois importantes dissacarídeos obtidos por isomerização da sacarose controle da obesidade. No geral, as suas propriedades físico-químicas permitem a substituição da sacarose na maioria dos alimentos doces e, em alguns casos, com bastantes vantagens.

Como a isomaltulose tem disponibilidade no mercado internacional, também é atraente como matéria-prima para a preparação de outros derivados sintéticos e, além disso, como sua ligação glicosídica é mais estável do que a da sacarose, há novas possibilidades de transformações químicas. Algumas transformações já são conhecidas e estão focadas principalmente na área da preparação polímeros biodegradáveis (Esquema 14) explorando a transformação da parte da frutose em glicosídeo do hidroximetilfurfural, sem alterar a parte da glicose. Com o aldeído estrategicamente posicionado no glicosilhidroximetilfurfural é possível fazer diversas transformações, tais como ésteres, amidas e derivados vinílicos para a preparação de novos produtos em escala industrial. ${ }^{99}$ Os ésteres derivados de cadeia longa apresentam propriedades tensoativas. ${ }^{100,101}$ Os derivados vinílicos podem ser úteis para preparação de polímeros biodegradáveis. ${ }^{102,103}$

Polióis são derivados de carboidratos reduzidos na carbonila e muitos destes produtos estão em uso no mercado sendo utilizados em uma grande variedade de alimentos, produtos farmacêuticos e nutracêuticos como, por exemplo, sorbitol, manitol, xilitol, lactitol etc. Estes alditóis ou polióis exploram algumas propriedades importantes para alguns segmentos do mercado de alimentos, como o sinergismo com outros edulcorantes, quantidade mínima de calorias por grama, não promover a cárie dentária e não aumentar os níveis de glicose no sangue ou insulina, além de ter manter o sabor e textura dos carboidratos. Além estes derivados exibirem doçura semelhante à sacarose, têm a vantagem de não sofrerem fermentação por ação de bactérias bucais. O sorbitol, produto de redução da glicose é, de longe, o mais popular dentre os alditóis, embora só uma pequena parcela da sua produção esteja destinada ao setor alimentício. A maioria do sorbitol produzido é consumida pelas indústrias de dentifrícios, pois age como umectante dos cremes dentais (retenção de água). Alguns alditóis são produzidos por processos biotecnológicos (enzimas e fermentação) como, por exemplo, o xilitol que pode ser obtido através de redução microbiológica com Candida gilliermondii. ${ }^{104}$

Seguindo esta tendência a isomaltulose foi reduzida por hidrogenação, somente na sua parte frutosídica, fornecendo uma mistura equimolecular de 6-O-( $\alpha$-D-glicopiranosil)-D-sorbitol e 1- $O$ - $(\alpha-\mathrm{D}$ glicopiranosil)-D-manitol (Esquema 14). Esta mistura epimérica é comercializada com o nome de Isomalt ${ }^{\circledR}$. A mistura tem sabor similar à sacarose e os produtos fabricados (ex. doces, chicletes, chocolates,

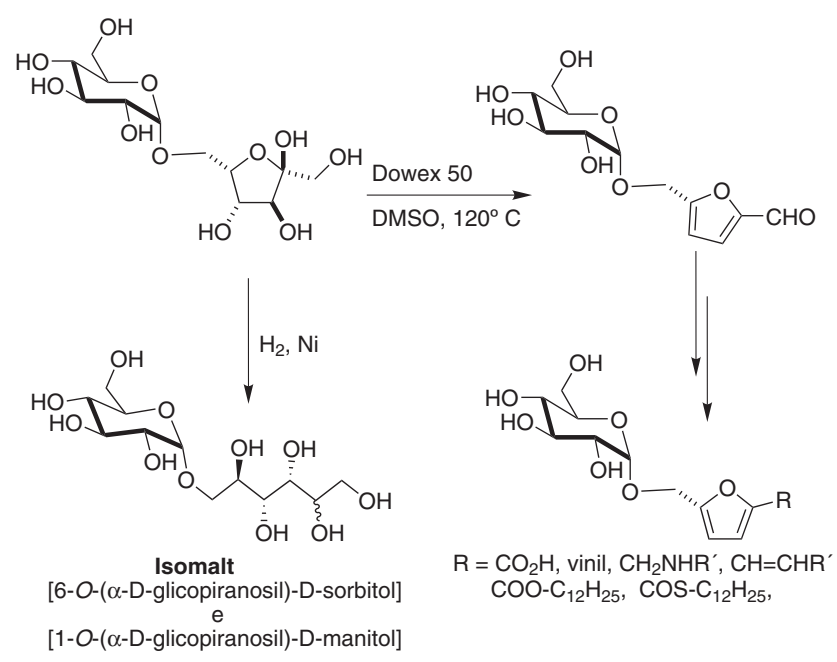

Esquema 14. Transformação química da isomaltulose em derivados furânicos e poliol 
enfornados, suplementos nutricionais, pastilhas, xaropes etc.) têm a mesma textura e aparência. O Isomalt ${ }^{\circledR}$, aprovado para uso nestes produtos desde o início de 1980, é um produto comercial versátil e valioso ingrediente de alimentos com teores calóricos reduzidos e produtos farmacêuticos.

A leucrose foi inicialmente descrita como um subproduto da produção de gomas dextrana a partir da sacarose como matéria-prima. ${ }^{105,106}$ Este dissacarídeo é menos doce do que a sacarose (50-60\%).

Existem diversos processos enzimáticos tecnicamente viáveis para a produção de grandes quantidades de leucrose pura. ${ }^{107}$ Este dissacarídeo é um edulcorante que pode ser usado como agente que evita a formação da placa bacteriana nos dentes. É especialmente adequado para diabéticos, pois tem uma menor taxa de clivagem da ligação glicosídica em relação à sacarose e a maltose e, assim, não produz um aumento do nível de glicose no sangue. ${ }^{108}$

\section{D-glicose}

A D-glicose é um dos carboidratos mais abundantes e, apesar de ser uma das unidades da sacarose, tem o amido como sua principal fonte de produção. ${ }^{100}$ Cerca de $34 \%$ do amido produzido ${ }^{109,110}$ é transformado em glicose. O conhecimento de sua química e bioquímica são bem desenvolvidos, tendo sua intensificação nas reações desenvolvidas por Emil Fischer que, em 1890, determinou sua configuração relativa com base em conversões oxidativas e redutoras e sobre a síntese da glicose a partir da extensão de arabinose por cianoidrina. ${ }^{111,112} \mathrm{~A}$ D-glicose é um açúcar redutor e em solução aquosa apresenta quatro estruturas cíclicas, furanosídicas e piranosídicas cada uma com dois estereoisômeros $\alpha$ e $\beta$ (epímeros) gerados no carbono hemiacetálico, também conhecido como carbono anomérico. A forma $\beta$-D-glicopiranose é a mais abundante em solução. ${ }^{113}$

Existe uma variedade de insumos industriais que podem ser obtidos a partir da glicose onde muitos deles são utilizados já na sua forma final como, por exemplo, alguns carboidratos (sorbitol, manose, sorbose, frutose, dextrinas, entre outros), o glicerol e o glicol ou como intermediários para obtenção de outros como alcoóis (como etanol), poliálcoois, aminoácidos, ácidos carboxílicos (como ácido cítrico, lático e acético) e até mesmo a vitamina C. ${ }^{113} \mathrm{O}$ Esquema 15 apresenta um fluxograma de alguns desses produtos químicos

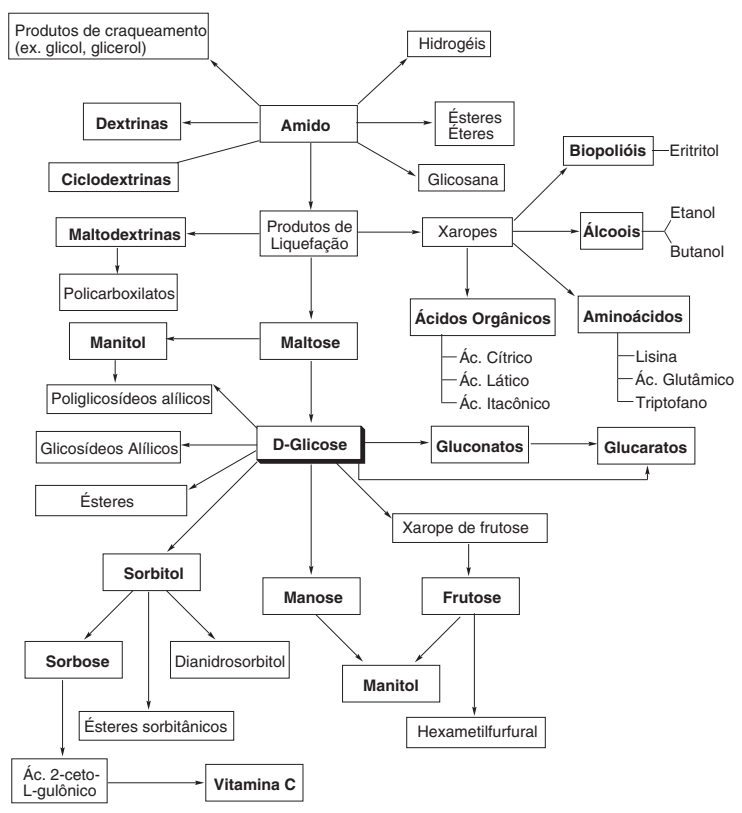

Esquema 15. Fluxograma de possibilidades de transformações de amido e glicose obtidos em escala industrial por processos químicos ou fermentativos (aeróbicos e anaeróbicos). ${ }^{12,114}$

Como mencionado anteriormente, o interesse sintético na Dglicose advém da possibilidade de sua transformação em substâncias acíclicas, furanosídicas ou piranosídicas. ${ }^{115}$ Por esses caminhos, um grande número de derivados é facilmente obtido utilizando-se reações simples, tais como oxidação, redução, aminação, cianidação, eterificação, glicosidação, esterificação, isomerização e epimerização. ${ }^{109}$

A D-glicose é utilizada em síntese orgânica para a preparação de substâncias que tenham cadeias lineares, anéis de cinco e seis membros. É o único carboidrato, juntamente com seus derivados, consideravelmente explorados em síntese orgânica como substratos, auxiliares e catalisadores quirais. Alguns derivados da D-glicose tornaram-se bem conhecidos dos químicos orgânicos, tais como o diacetonídeo da glicose ou simplesmente DAG, a $\delta$-gluconolactona e o metilglicosídeo-acetal do benzaldeído por serem comercialmente disponíveis ou facilmente preparados em laboratório (Esquema 16). Porém, várias outras pequenas rotas de transformação da D-glicose em substâncias quirais são conhecidas e bastante aplicadas em síntese orgânica. ${ }^{12,116}$

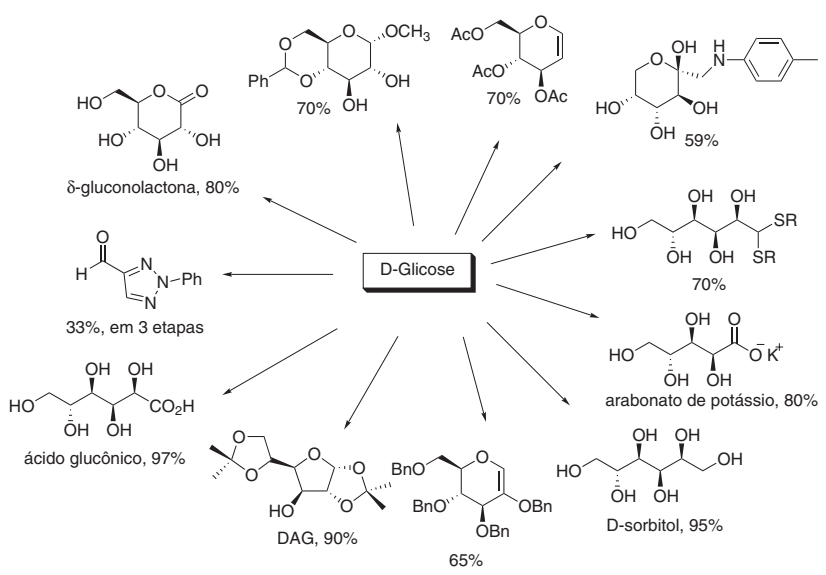

Esquema 16. Alguns derivados facilmente obtidos a partir de D-glicose

Dentre os três derivados da D-glicose citados anteriormente, o DAG continua sendo o mais utilizado. Pode-se dizer que esse é o derivado de carboidrato mais utilizado em síntese orgânica, como substrato, auxiliar e catalisador quirais. Seu uso tem sido limitado apenas a aplicações acadêmicas, porém o número de citações sobre sua utilização continua crescendo. A maioria das citações encontradas na literatura refere-se à aplicação do DAG em síntese de substâncias furanosídicas e como auxiliar de quiralidade, aplicado em várias reações onde há criação de um ou mais centros quirais. ${ }^{117}$

Outro derivado da D-glicose muito difundididoé a $\delta$-gluconolactona que é um acidulante para alimentos, que pode ser obtida a partir ácido glucônico (por diferentes procedimentos) ${ }^{118}$ sendo obtido a partir da glicose em $97 \%$ de rendimento por oxidação do carbono anomérico por via química, ${ }^{119}$ eletroquímica ou fermentativa. ${ }^{120}$ Sua produção mundial atinge cerca de 30.000.000 t/ano ao preço de US\$ 0,39/kg. Uma parte desse ácido é transformada em alguns sais de ampla utilização em química fina, como o gluconato de cálcio que apresenta as mais diversas aplicações no mercado, tais como a de conservantes químicos para linguiças, potencializador anti-histamínico, polidor de metais, pasta de dente etc. Já o gluconato de sódio é usado na formulação de detergentes, lavagens de garrafas, desoxidação e remoção de pinturas automotivas etc. ${ }^{121} \mathrm{~A}$ outra parte é transformada em $\delta$ e $\gamma$-lactonas a partir de soluções super saturadas a uma temperatura de $30-70{ }^{\circ} \mathrm{C}$.

$\mathrm{O}$ interesse no uso de aldonolactonas comercialmente disponíveis, como substratos quirais em síntese de produtos naturais, tem aumentado consideravelmente. ${ }^{122.123}$ Dentre suas várias aplicações 
pode-se selecionar alguns de seus acetonídeos lineares, mostrados no Esquema 17, que são utilizados na síntese de outros açúcares ${ }^{124}$ como, por exemplo, a D-arabinose. É importante ressaltar que a $\delta$-gluconolactona não forma acetonídeos cíclicos.

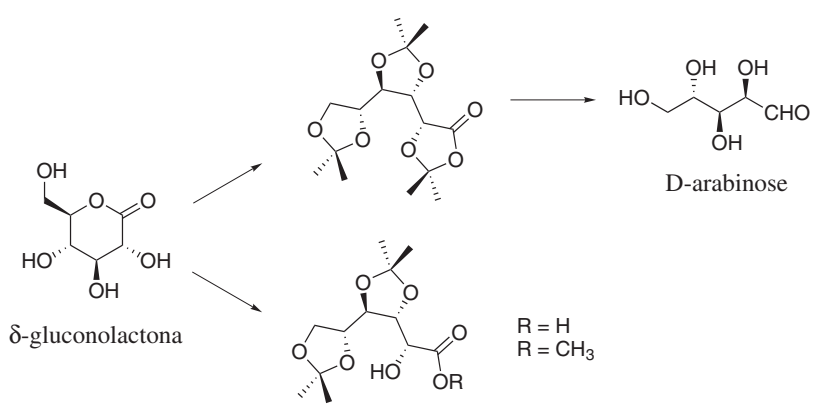

Esquema 17. Alguns intermediários obtidos da $\delta$-gluconolactona

\section{D-frutose}

A D-frutose é um carboidrato largamente usado como adoçante em bebidas, uma vez que é 1,5 vezes mais doce do que a sacarose. Uma solução aquosa de D-frutose consiste de uma mistura de quatro tautômeros cíclicos, dos quais apenas a $\beta$-D-piranose apresenta sabor doce à temperatura ambiente. Este carboidrato pode ser preparado em grandes quantidades, onde o principal método se constitui na isomerização da glicose derivada de amido, empregando catálise básica. Outros métodos consistem da hidrólise da inulina de alcachofra de Jerusalém (Helianthus tuberosus) e outras espécies vegetais. ${ }^{11}$

A frutose tem sido incorporada com sucesso a formulações no preparo de frutas enlatadas, geléias, doces em pasta, bolos, pudins, tabletes, pó para bebidas, refrigerantes etc. Seu custo vem sendo reduzido gradualmente ao longo dos anos como resultado da melhoria nos seus processos de obtenção. Em 1969 seu custo, na Europa, era de US\$17,6/ $\mathrm{kg}^{15}$ enquanto que atualmente é negociado por US\$1,3/ $\mathrm{kg}$ com uma produção anual de 60.000 toneladas. ${ }^{113}$

A sua utilização em produtos que não tenham aplicação alimentar é muito pequena, o que não chega a ser uma surpresa já que a química básica relacionada a este carboidrato é muito pouco desenvolvida quando comparada à D-glicose, o que está associado com o equilíbrio tautomérico entre as duas formas piranosídicas e as duas furanosídicas, em torno de $50 \%$. ${ }^{125}$ No entanto, existem várias reações a partir da frutose que podem explorar o seu potencial em aplicações industriais. Dois aspectos devem ser ressaltados: sua transformação mantendo intacto o anel pirânico e transformação em derivados contendo o anel furânico.

A obtenção de derivado da frutose em cadeia aberta é muito raro. Porém, mantendo o anel pirânico existem mais transformações desenvolvidas. Dentre estes, destacam-se em síntese orgânica os diacetonídeos DAF-1 e DAF-2, os quais têm sido utilizados como auxiliares ${ }^{126,127}$ e reagentes quirais. Cabe ressaltar que existe um processo mais econômico para a obtenção do DAF-1 também a partir da sacarose (Esquema 18). ${ }^{128,129}$ Outros derivados pirânicos com potencial utilidade por serem obtidos por reações simples e seletivas incluem: monoalil-, 2-cloroetil- $\beta$-frutopiranosídeos, poliacetilado, ${ }^{130,131}$ benzoilado, cetais ${ }^{132}$ e 1,2-espiro-anelados. ${ }^{133,134}$

As principais aplicações da D-frutose fora do contexto alimentar correspondem à produção de hidroximetilfurfural (HMF) e ácido levulínico. ${ }^{11,19}$ Os derivados do HMF são intermediários de elevado potencial industrial, os quais possuem síntese adaptável para larga escala. Destes, o ácido 5-hidroximetilfuróico, ácido 2,5-dicarboxílico, 1,6-diamina e o respectivo 1,6-diol são os intermediários mais versáteis e de elevado potencial industrial, uma vez que são

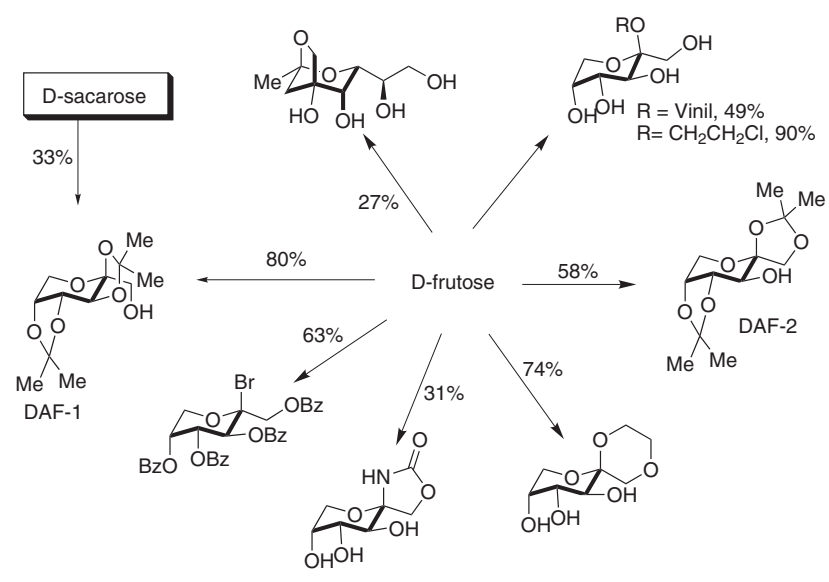

Esquema 18. Importantes derivados pirânicos obtidos a partir da frutose

monômeros de seis carbonos que podem substituir o ácido adípico, ou alquildióis, ou hexametilenodiamina na produção de poliamidas e poliésteres (Esquema 19).

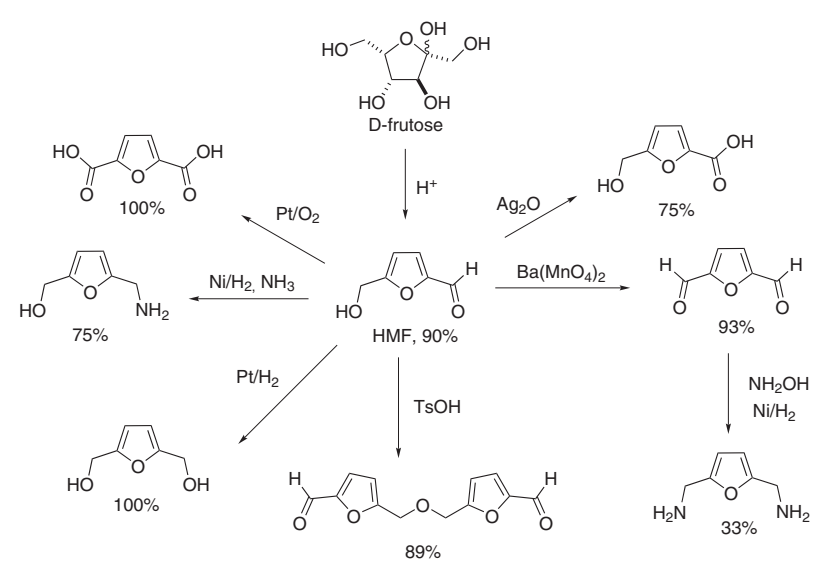

Esquema 19. Síntese de produtos furânicos obtidos a partir da frutose

Embora seja de grande utilidade, deve-se ressaltar que o HMF ainda não é produzido industrialmente uma vez que seu preço de mercado gira em torno de US\$ 3200 por tonelada, um valor bastante elevado quando comparado com matérias-primas de uso industrial derivadas do petróleo, como a nafta e etileno (US\$ 190-500 por tonelada). ${ }^{113}$

Recentemente, verificou-se a possibilidade de produção de energia elétrica a partir de carboidratos, dentre eles a D-frutose, utilizando células combustíveis à base de micro-organismos, apresentando-se como uma fonte de energia renovável a partir de biomassas ${ }^{135}$ e que futuramente podem se apresentar como uma boa alternativa à utilização de combustíveis fósseis.

\section{D-manitol}

O D-Manitol é um carboidrato natural encontrado em diversos vegetais como beterraba, cebola, aipo, figo e azeitonas (Esquema 20). Também está presente em alguns exsudatos de árvores e algas marinhas, dos quais pode ser obtido por meio de extração com álcool a quente. O maná ${ }^{136}$ obtido da Fraximus ornus (Fam. Oleaceae) pode conter de 60 a $90 \%$ deste carboidrato. ${ }^{137}$ Este carboidrato não pode ser considerado como abundante na natureza e sua distribuição taxonômica é limitada. Portanto, sua extração comercial de fontes naturais não é economicamente viável. Entretanto, ele é industrialmente obtido a partir da mistura de D-sorbitol e D-manitol (Esquema 20), que é 
obtida pela redução do açúcar invertido, uma mistura equimolecular comercial de glicose e frutose derivada da hidrólise da sacarose.
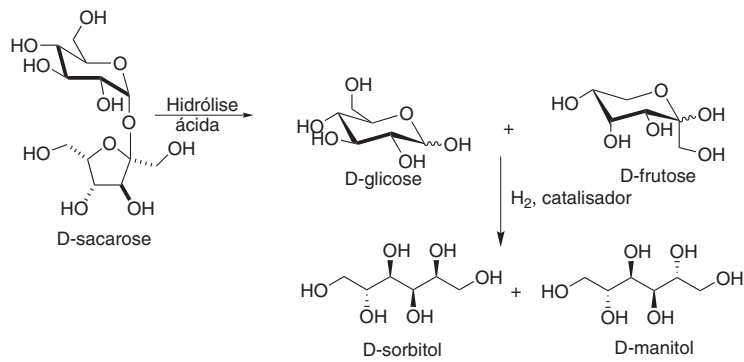

Esquema 20. Hidrólise da sacarose e redução à mistura sorbitol/manitol

Por ser um poliol altamente versátil e de baixo custo, é bastante utilizado para os mais diversos fins comerciais e científicos. ${ }^{138}$ Algumas destas aplicações estão resumidas no Esquema 21. Na indústria farmacêutica, é usado como excipiente em comprimidos, especialmente aqueles destinados a dissolverem-se na boca, devido à agradável sensação de doçura e frescor mencionados anteriormente. É um carboidrato incapaz de ser absorvido no trato gastrointestinal, sendo eliminado com facilidade por filtração glomerular. Desta forma, o D-manitol encontra aplicação na medicina ${ }^{139}$ como um diurético osmótico, sendo utilizado em neuroanestesia e neurorreanimação ${ }^{140}$ para diminuir o volume e edemas cerebrais em pacientes com traumatismo craniano ${ }^{141} \mathrm{e}$ a pressão intraocular. É um edulcorante bastante atraente do ponto de vista da indústria alimentícia dietética, pois é um carboidrato que possui valor calórico reduzido, uma vez que é absorvido apenas parcialmente no intestino delgado. O restante é metabolizado por bactérias presentes no intestino grosso. Além disso, a pouca quantidade que é absorvida, não depende da insulina para que seja metabolizada.

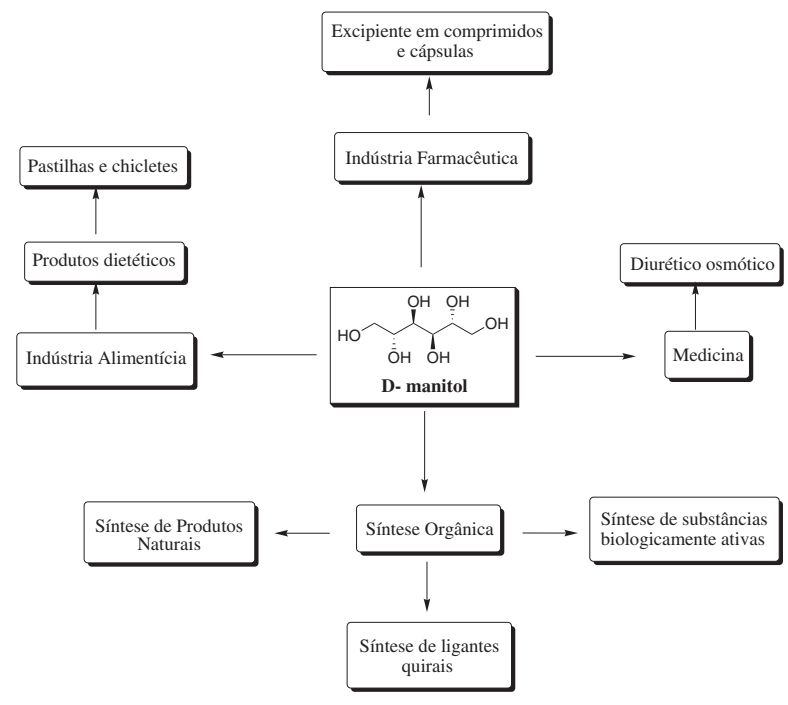

Esquema 21. Algumas aplicações para o D-manitol

Do ponto de vista estrutural, o D-manitol possui eixo de simetria $C_{2}$ e quatro centros estereogênicos. Essas características, aliadas ao baixo custo, permitiram que fosse utilizado amplamente na síntese de diversos ligantes quirais com o objetivo de serem aplicados em reações de catálise assimétrica. A sua utilidade em síntese orgânica ultrapassa em muito apenas este aspecto. Do ponto de vista da síntese orgânica, o D-manitol é um excelente material de partida para síntese de blocos de construção quiral (chiral building blocks) ${ }^{15}$ úteis na obtenção de diversos compostos enantiomericamente puros e biologicamente ativos (Esquema 22). No que diz respeito à síntese de produtos naturais, o D-manitol já foi extensivamente utilizado para obtenção de substâncias bastante complexas.

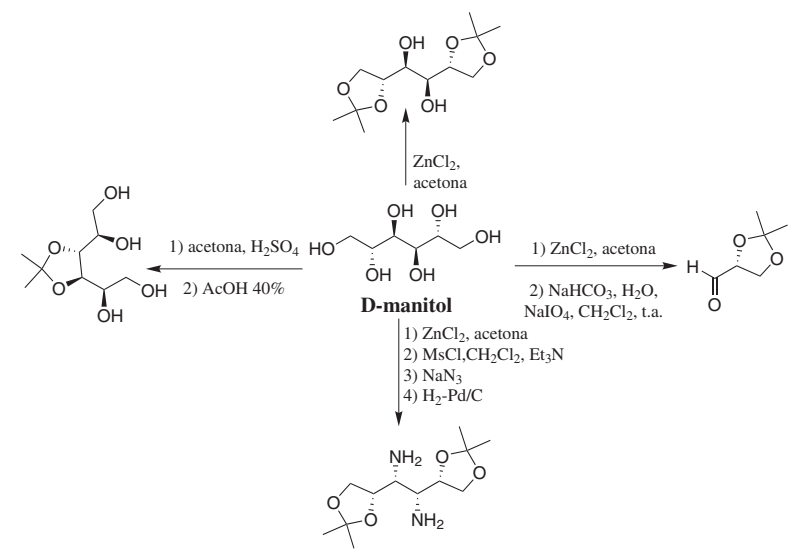

Esquema 22. Importantes derivados do D-manitol obtidos em poucas etapas

\section{Ciclodextrinas (CDS)}

As ciclodextrinas (CDs) são carboidratos complexos compostos de unidades de glicose ( $\alpha$-D-glicopiranose) unidas por ligações tipo $\alpha-1,4$, com estrutura semelhante a um tronco de cone. ${ }^{142,143} \mathrm{~A}$ primeira referência sobre estas substâncias que mais tarde seriam classificadas como ciclodextrinas foi publicada por Villiers em 1891, em um estudo sobre a digestão do amido com o Bacillus amylobacter, o qual denominou de celulosina. ${ }^{144}$ Em 1903, Franz Schardinger identificou as ciclodextrinas como produtos resultantes da degradação do amido pela ação da enzima amilase ciclodextrina glicosil transferase (CGTase) ${ }_{1}^{145}$ produzida pelo micro-organismo Bacillus macerans, capaz de romper um segmento da hélice do amido e unir as duas porções terminais deste fragmento numa única molécula cíclica. ${ }^{146}$ Por modificação enzimática é possível obter ciclização de seis, sete ou oito unidades de glicose, dando origem à $\alpha, \beta$ e $\gamma$-CD, respectivamente (Esquema 23). ${ }^{147}$

As CDs mais amplamente empregadas para fins comerciais e científicos são as $\alpha, \beta$ e $\gamma$, formadas por seis, sete e oito unidades

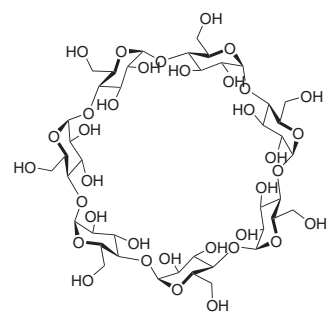

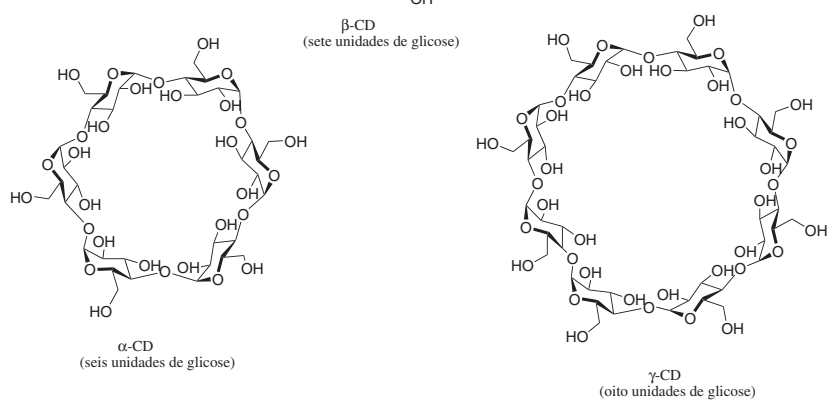

Esquema 23. Estruturas moleculares de $\alpha, \beta$ e $\gamma$-ciclodextrinas 
de D-glicose, respectivamente (Esquema 23). ${ }^{148,149}$ Basicamente, as ciclodextrinas apresentam este nome genérico por serem formadas por unidades de dextrose, antigo sinônimo de glucose, e a letra grega serve para a diferenciação entre os membros de uma série homóloga. Assim, $\alpha-, \beta-, \gamma-, \delta-, \varepsilon_{-}, \ldots$ correspondem às ciclodextrinas com 6,7 , $8,9,10, \ldots$ unidades de $\mathrm{D}$-glicopiranose, respectivamente.

No estado natural são moléculas rígidas, cristalinas e homogêneas, que oferecem inúmeras utilidades em função do seu tamanho, sua forma e de grupos funcionais livres. ${ }^{150}$ Sua estrutura física foi estabelecida, em 1942, por estudos de difração raios- $X^{151,152}$ que mostraram que estas moléculas anulares possuem as hidroxilas primárias na parte mais estreita do tronco, ao passo que as hidroxilas secundárias encontram-se na sua parte mais larga. As hidroxilas das extremidades tornam as ciclodextrinas solúveis em água, devido à possibilidade de formação de ligações de hidrogênio com o solvente. Por outro lado, o interior da cavidade é delimitado pelo alinhamento dos hidrogênios $\mathrm{C}(3)-\mathrm{H}$ e C(5)-H e pelo oxigênio da ligação éter C(1)-O-C(4), o que lhes confere caráter hidrofóbico (Esquema 24). ${ }^{153}$
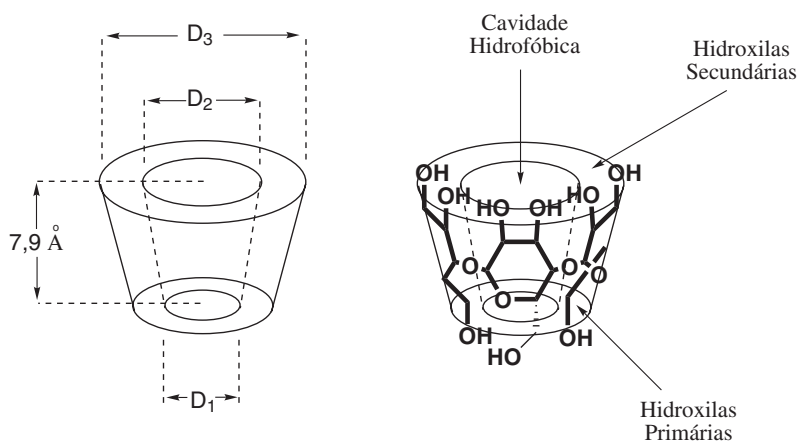

Esquema 24. Representação esquemática da estrutura funcional das CDs

São conhecidas inúmeras aplicações para as CDs na indústria de agroquímicos, fragrâncias, alimentícia, farmacêutica etc. Porém, uma das propriedades mais importantes é a sua capacidade de formar complexos de inclusão com uma grande variedade de moléculas hóspedes (compostos orgânicos ou inorgânicos, de natureza neutra ou iônica) em solução. ${ }^{146,154}$ Estes complexos de inclusão vêm sendo utilizados em produtos farmacêuticos (Esquema 25), ${ }^{155}$ alimentícios e agrícolas. Nesses produtos, as CDs agem principalmente como veículos de solubilização em água, porque as substâncias apolares estão no interior do cone, e a interação com a água é feita com a parte exterior polar do tronco. ${ }^{156}$

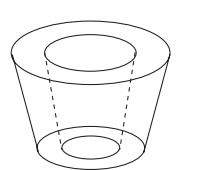

$\mathrm{CD}$

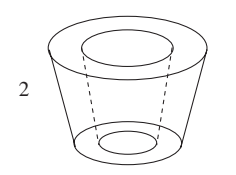

$\mathrm{CD}$

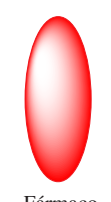

Fármaco

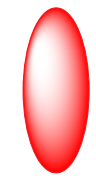

Fármaco

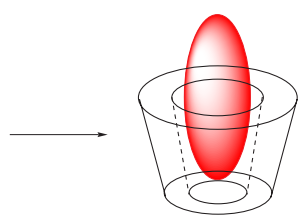

Complexo 1:1 fármaco-CD

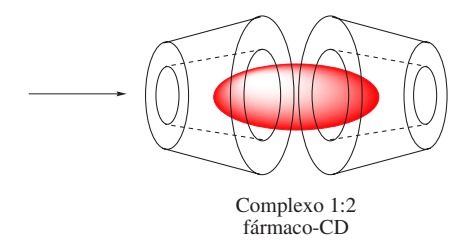

fármaco-CD
Esquema 25. Complexos fármaco-ciclodextrinas

O conhecimento básico das ligações e das catálises enzimáticas, associado às propriedades estruturais das CDs (cavidade hidrofóbica de tamanho apropriado, sítios para a introdução de grupos catalíticos e satisfatória solubilidade em água), tem levado ao desenvolvimento de modelos simples de enzimas artificiais, numa tentativa de mimetizar reações biológicas mais específicas. ${ }^{157,158}$ Da mesma forma que muitas enzimas utilizam coenzimas para promoverem reações catalíticas específicas, tais grupos podem ser sintetizados e conectados às CDs, criando assim enzimas-coenzimas artificiais nas quais a cavidade hidrofóbica atua como o sítio ativo da enzima que complexa com o substrato, enquanto a porção funcionalizada age mimetizando uma coenzima. Na literatura, ${ }^{159}$ existem muitos exemplos destas enzimascoenzimas artificiais, ${ }^{160,161}$ como o de ciclodextrinas funcionalizadas com grupos que mimetizam o pirofosfato de tiamina ${ }^{162}$ (coenzima responsável pela descarboxilação de $\alpha$-cetoácidos), fosfato de piridoxamina ${ }^{163}$ (coenzima responsável pela transaminação e outras transformações de aminoácidos), vitamina $\mathrm{B}_{12}\left(\text { coenzima } \mathrm{B}_{12}\right)^{164} \mathrm{e}$ outras. ${ }^{165}$

As CDs desempenham um importante papel na química medicinal no que diz respeito à tecnologia de liberação controlada de fármacos, que representa atualmente uma das fronteiras da ciência envolvendo diferentes aspectos multidisciplinares. Os sistemas de liberação, frequentemente descritos como drug delivery systems, oferecem inúmeras vantagens quando comparados a outros de dosagem convencional, pois estas formulações alteram substancialmente certos parâmetros farmacocinéticos como, por exemplo, a meia-vida do fármaco, sua depuração do organismo e seu volume de distribuição. Ademais, a toxicidade de medicamentos é também drasticamente reduzida com o emprego destas formas. ${ }^{166} \mathrm{Na}$ indústria farmacêutica, as CDs são utilizadas principalmente como substâncias auxiliares que melhoram a estabilidade, a biodisponibilidade e as propriedades organolépticas, como o sabor e o cheiro, de substâncias ativas em formulações farmacêuticas. As CDs podem ser utilizadas para a supressão de volatilidade, a transformação de compostos líquidos em sólidos, mascarar o cheiro desagradável e o sabor de alguns fármacos, evitar incompatibilidades indesejáveis etc. $\mathrm{O}$ aumento da solubilidade, dissolução, taxa de liberação e biodisponibilidade, a modificação da farmacocinética, a modificação da disposição de fármacos, a liberação controlada de fármacos e a terapia dirigida/alvo são também algumas das possíveis aplicações de CDs. Elas também têm sido usadas na redução de efeitos colaterais de fármacos, na inibição de efeitos catalíticos (estabilidade química e física), no aumento da estabilidade na presença da luz, calor e condições de oxidação e, também, em análises cromatográficas. As CDs vêm sendo empregadas com sucesso na administração e liberação de fármacos por várias vias e/ou locais de administração, como oral, vaginal, retal, nasal, oftálmica, pulmonar, dérmica e transdérmica.

No entanto, apesar da biocompatilidade das CDs, estas podem mostrar, por exemplo, resistência ao poder de degradação de enzimas humanas. As CDs podem ser tóxicas dependendo de sua rota de administração. Quando aplicadas por via intravenosa em humanos são excretadas, inteiramente, pelos rins. Os valores de $\mathrm{LD}_{50}$ para $\alpha$-, $\beta$ - e $\gamma$-CD por administração intravenosa em ratos são aproximadamente de $1,0,{ }^{167} 0,79$ e mais do que $4,0 \mathrm{~g} / \mathrm{kg},{ }^{168}$ respectivamente. Adicionalmente, em determinadas concentrações, a $\beta$-CD tem uma grande afinidade com colesterol podendo carreá-lo da membrana lipídica de células ${ }^{169} \mathrm{e}$, em concentrações suficientemente altas, pode causar hemólise dos eritrócitos. A administração parenteral de $\beta-C D$ não é possível devido a sua baixa lipofilicidade, que a faz precipitar como microcristais nos rins, além do fato de formar complexos com o colesterol que se acumulam nos rins danificando os néfrons. A funcionalização da $\beta$-CD pode suavizar este problema.

As associações de CDs com fármacos aumentam a solubilidade, a biodisponibilidade e ainda a estabilidade do princípio ativo. Essa associação pode ainda converter princípios ativos líquidos ou oleosos 
Tabela 2. Complexos fármaco-CD comerciais disponíveis no mercado farmacêutico mundial

\begin{tabular}{|c|c|c|c|}
\hline Complexo & Nome Comercial & Indicação & Companhia/País \\
\hline $\mathrm{PGE}_{2} / \beta-\mathrm{CD}$ & Prostarmon E & Inibidor de parto & Ono (Japão) \\
\hline $\mathrm{PGE}_{2} / \alpha-\mathrm{CD}$ & Prostavasin & Doença arterial oclusiva & Ono (Japão) \\
\hline Piroxicam $/ \beta-C D$ & Cicladol/Brexin & Anti-inflamatório/ Analgésico & Masterpharma/Chiesi (Itália) \\
\hline Iodo/ $\beta-\mathrm{CD}$ & Mena-Gargle & Infecção na garganta & Kyushin (Japão) \\
\hline Dexametasona, Glyteer/ $\beta$-CD & Glymesason & Anti-inflamatório/ Analgésico & Fujinaga (Japão) \\
\hline Chloramphenicol $/ \beta-C D$ metilada & Clorocil & Antibiótico & Oftalder (Portugal) \\
\hline Piroxicam/ $\beta-C D$ & Flogene & Anti-inflamatório/ Analgésico & Aché (Brasil) \\
\hline Nicotina//3-CD & Nicorette & Dependência em Nicotina & Pharmacia Upjohn (Suécia) \\
\hline Omeprazo/ $\beta-\mathrm{CD}$ & Omebeta & Antiulceroso & Betapharm (Alemanha) \\
\hline Diclofenaco $\mathrm{Na} /$ Hidróxipropil/ $\gamma-\mathrm{CD}$ & Voltaren oftalmico & Anti-inflamatório & Novartis (Suíça) \\
\hline
\end{tabular}

em sólidos pulverizáveis de fácil manipulação e reduzir a evaporação de substâncias voláteis, odores e sabores fortes.

Existem vários exemplos de complexos fármaco-CDs na indústria farmacêutica. Por exemplo, o fármaco Cycloazelon, comercializado pela GERBRAS, é um complexo de inclusão, entre a $\beta$-ciclodextrina (hospedeira) e o ácido azeláico (ácido nonadioico, molécula hóspede) em uma concentração de $50 \% .{ }^{170}$ Outro exemplo é o complexo $\beta$-ciclodextrina/piroxicam comercializado pela Farmalab Chiesi Indústrias Farmacêuticas, sob o nome de Cicladol ${ }^{\circledR}$. Trata-se de um anti-inflamatório não-esteroidal altamente hidrossolúvel, que é absorvido mais rapidamente por administração oral e retal do que o piroxicam. ${ }^{171}$

Apesar do grande número de complexos fármaco-CDs comercializados no mercado farmacêutico mundial (Tabela 2), estes ainda tem sido associados apenas a fármacos com baixas massas moleculares. ${ }^{168,172}$ No futuro são esperadas novas aplicações de CDs, mas é na química medicinal que são esperadas as grandes novidades.

Outro aspecto das aplicações das CDs que vem ganhando destaque atualmente envolve seu uso no desenvolvimento de metodologias para a remoção do caráter tóxico (destoxificação) de muitos compostos potencialmente agressivos aos sistemas vivos. ${ }^{173}$ Os hidrocarbonetos clorados são compostos de alta toxicidade, sendo que os que são voláteis causam efeitos deletérios sobre a camada de ozônio, enquanto os compostos bifenílicos policlorados (PCBs) são reconhecidos pelo seu impacto social sobre a saúde humana. ${ }^{174}$ Estudos vêm sendo feitos atualmente com o objetivo de se aplicar CDs no desenvolvimento de metodologias que visam a degradação destes compostos.

As CDs formam complexos com uma variedade de compostos utilizados na área agrícola, tais como herbicidas, ${ }^{175}$ fungicidas, ${ }^{176}$ inseticidas, ${ }^{177}$ feromônios ${ }^{178}$ e reguladores de crescimento, ${ }^{179}$ sendo estes trabalhos de interesse especial devido à formação destes complexos de inclusão geralmente resultar em melhorias nas propriedades físicoquímicas dos agroquímicos, tais como o aumento da solubilidade e da biodisponibilidade, o aumento da estabilidade no caso de compostos instáveis ou fotodegradáveis, a redução do aroma desagradável e da toxicidade em sistemas vivos. ${ }^{180,181}$ As aplicações potenciais das CDs nesta área atendem ainda a outras questões importantes, tais como a liberação controlada dos substratos, biodegradabilidade da molécula receptora, possibilidade de efeitos catalíticos sobre a degradação de pesticidas e mesmo a solubilidade dos complexos formados em água, o que deve permitir a fácil remoção dos agroquímicos no solo.

A preparação de cosméticos é outra área na qual se utiliza a complexação de moléculas com CDs como, por exemplo, na diminuição da volatilidade de perfumes. A estabilização, o controle do odor e o aperfeiçoamento do processo envolvendo a conversão de um ingrediente líquido para a forma sólida são os principais benefícios dessas macromoléculas neste setor. ${ }^{182} \mathrm{~A}$ complexação de triclosan com CDs aumentou a disponibilidade do antimicrobiano na formulação de uma pasta dental. ${ }^{183} \mathrm{~A}$ interação de aromas com CDs é ainda de especial interesse para a indústria de alimentos ${ }^{184}$ e no desenvolvimento de produtos têxteis aromoterápicos. ${ }^{185}$

\section{CONCLUSÃO}

O Brasil é um país com grande potencial de geração de diversos tipos de biomassas e, portanto, deve ter programas de pesquisas focalizados para o desenvolvimento de tecnologias capazes de utilizá-las para a produção de insumos químicos básicos e intermediários da química fina. Em se tratando de biomassas baseadas em carboidratos as oportunidades são enormes e estas não devem ser encaradas somente como matérias-primas para a produção de combustíveis, mas também para a fabricação de novos intermediários químicos e materiais de maior valor agregado.

Não são novas as opiniões sobre as preocupações ambientais, em especial sobre mudanças climáticas e sobre o uso de combustíveis fósseis, porém recentemente elas aumentaram as pressões sobre estes combustíveis e materiais oriundos destas fontes. Pode-se dizer que estas pressões estão causando uma espécie de revolução nas agendas políticas dos países líderes e o Brasil deve encará-la corretamente para poder seguir numa era de melhores condições em termos de saúde pública, riqueza e prosperidade, através da exploração racional, sustentável e ambientalmente aceitável dos nossos recursos naturais. A implantação de um programa grandioso como o Pró-Álcool nos credencia como líderes nesta revolução. No entanto, devemos fazêlo corretamente, e temos de aprender com os erros, de um século de crescimento, que usavam tecnologia baseada em avaliações econômicas e sociais incompletas e míopes para alimentar uma sociedade impulsionada pela ganância e pelo consumismo ao invés da necessidade. Os recursos renováveis e a sustentabilidade devem ser questões indissociáveis com políticas de valorização integral da produção.

Em outro patamar, é preciso que as empresas se conscientizem da importância desta nova tendência e invistam em novas tecnologias baseadas em recursos renováveis que serão importantes para o desenvolvimento de negócios sustentáveis. Para que as tecnologias advindas destas matérias-primas sejam economicamente viáveis são necessários estudos e a formação de recursos humanos nas áreas de biologia, fisiologia, agricultura até o processo químico, dentre outros. Deste fato resulta que não existe um único profissional especialista em todas estas diferentes áreas e, portanto, o uso das biomassas reno- 
váveis tem uma forte atividade de integração entre química, biologia, bioquímica, ciências agrárias, tecnologia ambiental e economia.

\section{AGRADECIMENTOS}

F. C. da Silva e D. R. da Rocha agradecem à FAPERJ e ao CNPq as bolsas de pós-doutorado e doutorado, respectivamente. Especial agradecimento ao Projeto Rede-Águas da UFF.

\section{REFERÊNCIAS}

1. Santos, A. P. B.; Pinto, A. C.; Química Nova na Escola 2008, n. 30, 1.

2. Suarez, P. A. Z.; Meneghetti, S. M. P.; Ferreira, V. F.; Quim. Nova 2006, 29, 1157.

3. Pinto, A. C.; Guarieiro, L. L. N.; Rezende, M. J. C.; Ribeiro, N. M.; Torres, E. A.; Lopes, W. A.; Pereira, P. A. P.; Andrade, J. B.; J. Braz. Chem. Soc. 2005, 16, 1313.

4. Galembeck, F. Em Brazilian Network on Green Chemistry: Awareness, Responsibility and Action; Carioca, J. O. B., ed.; Editora UFC: Fortaleza, 2008, p. 217.

5. Kamm, B.; Kamm, M.; Gruber, P. R.; Kromus, S. Em Biorefineries Industrial Processes and Products. Status Quo and Future Directions; Kamm, B.; Gruber, P. R.; Kamm, M., eds.; Wiley-VCH Verlag GmbH \& Co. KgaA: Weinheim, 2006, vol .1, p. 3.

6. Storcker, M.; Angew. Chem., Int. Ed. 2008, 47, 2.

7. Schuchardt, U.; Ribeiro, M. L.; Gonçalves, A. R.; Quim. Nova 2004, 24, 247.

8. Leite, A. L. S.; Laeal, M. R. L. V. Em Brazilian Network on Green Chemistry: Awareness, Responsibility and Action, Carioca, J. O. B., ed.; UFC: Fortaleza, 2008, p. 217.

9. Karlivan, V. P. Em CHEMRAWN I: Future Sources of Organic Raw Materials; St.-Pierre, L.E.; Brows, G. R., eds.; Pergamon Press: Elmsford, 1980.

10. Lichtenthaler, F. W. Em Biorefineries, Industrial Processes and Products; Kamm, B.; Gruber, P. R.; Kamm, M., Eds.; Wiley-VCH, Weinheim, 2006, Vol. 2, 3.; Lichtenthaler, F. W.; Carbohydrates; 6 $^{\text {th }}$ ed., Ullmann's Encyclopedia of Industrial Chemistry; 2002; Lichtenthaler, F. W. em Carbohydrates as Raw Materials for the Chemical Industry, Tundo, P, ed., Green Chemistry Series, $3^{\text {rd }}$ ed., INCA, Veneza, 2004, 105.

11. Lichtenthaler, F. W.; Acc. Chem. Res. 2002, 35, 728.

12. Lichtenthaler, F. W.; Peters, S.; C. R. Chim. 2004, 7, 65.

13. Pinheiro, S.; Ferreira, V. F.; Quim. Nova 1998, 21, 312.

14. Bols, M.; Carbohydrate building blocks, John Wiley \& Sons, Inc.: New York, 1996.

15. Ferreira, V. F; Quim. Nova 1995, 18, 267.

16. da Rocha, D. R.; Ferreira, V. F.; Santos, W. C.; Revista Processos Quími$\cos \mathbf{2 0 0 8 , 2 , 9 .}$

17. Stick, R. V.; Carbohydrates: The Sweet Molecules of Life, Academic Press, 2001.

18. Okkerse, C.; van Bekkum, H.; Green Chem. 1999, 1, 107.

19. Stevens, C. V.; Verhé, S. R.; Renewable Bioresources Scope and Modification for Non-food Applications, Eds. C. V.; John Wiley \& Sons, Chichester, 2004.

20. Assis, O. B. G.; Silva, V. L.; Polímeros 2003, 13, 223.

21. Santos, J. E.; Soares, J. P.; Dockal, E. R.; Filho, S. P. C.; Cavalheiro, E. T. G.; Polímeros: Ciência e Tecnologia 2003, 13, 242.

22. Silva, H. S. R. C.; dos Santos, K. S. C. R.; Ferreira, E. I.; Quim. Nova 2006, 29, 776.

23. Brown Jr., R. M.; Saxena, I. M.; Kudlicka, K.; Trends Plant Sci. 1996, $1,149$.

24. Joshi, C. P.; Mansfield, S. D.; Curr. Opinion Plant Biol. 2007, 10, 220.

25. Nishiyama Y., Langan P., Chanzy, H.; J. Am. Chem. Soc., 2002, 124, 9074; Nishiyama, Y., Sugiyama, J., Chanzy, H., Langan, P. J. Am. Chem. Soc., 2003, 125, 14300 .
26. Festucci-Buselli, R. A., Otoni, W. C., Joshi, C. P.; Braz. J. Plant Physiol. 2007, 19, 1.

27. Soares, N. S.; da Silva, M. L.; de Lima, J. E.; Rev. Árvore 2007, 31, 495.

28. Valverde, S. R.; Soares, N. S.; Silva, M. L.; Rev. Árvore 2006, 30, 1017.

29. Prochazkova, S.; Varum, K. M.; Ostgaard, K.; Carbohydr. Polym. 1999, 38,115 .

30. Novikov, V. Y. U.; Ivanov, A. L.; Patente RU2042685-C1, 1992

31. Filho, S. P. C.; Signini, R.; Cardoso, M. C.; Revista Processos Químicos 2007, 2, 9 .

32. Kumar, M. N. V. R.; React. Funct. Polym. 2000, 46, 1.

33. Muzzarelli, R. A. A.; Cell. Mol. Life Sci. 1997, 53, 131.

34. dos Santos, K. S. C. R.; Silva, H. S. R. C.; Ferreira, E. I.; Bruns, R.; Carbohydr. Polym. 2005, 59, 37.

35. Heras, A.; Rodriguez, N. M.; Ramos, V. M.; Agullo, E.; Carbohydr. Polym. 2001, 44, 1; Ramos, V. M.; Rodríguez, N. M.; Rodríguez, M. S.; Heras, A.; Agulló, E.; Carbohydr. Polym. 2003, 51, 425.

36. Ramos, V. M.; Rodríguez, N. M.; Díaz, M. F.; Rodríguez, M. S.; Heras, A.; Agulló, E.; Carbohydr. Polym. 2003, 52, 39.

37. Muzzarelli, R.; Wecky, M.; Filippini, O.; Lough, C.; Carbohydr. Polym. 1989, 11, 307.

38. Rinauldo, M.; Desbriéres, J.; Le Dung, P.; Thuy Binh, P.; Dong, N. T.; Carbohydr. Polym. 2001, 46, 339.

39. Chen, X. -G.; Park, H. -J.; Carbohydr. Polym. 2003, 53, 355.

40. Silva, H. S. R. C.; dos Santos, K. S. C. R.; Fagundes, F. P.; Garcia, R. B.; Ferreira, E. I.; Rev. Bras. Cienc. Farm. 2003, 39, supl. 3, 87.

41. Emmons, C. H. H.; Kuster, B. F. M.; Sheldon, R. A.; Tetrahedron: Asymmetry 1991, 2, 359; Rossiter, B. T.; Swingle, M. M.; Chem. Rev. 1992, 92, 771; Draths, K. M.; Wards, T. L.; J. Am. Chem. Soc. 1992, 114, 975.

42. Strong, L. A. G.; The Story of Sugar, Academic Press, Londres, 1954.

43. http://www.bettersugarcane.org acessada em Novembro 2008.

44. Willians, R.; Sucrochemistry: Chemical Fermentation; R. F. Gould, ed.; ACS Symposium Series 41, 1977, 274.

45. Carioca, J. O. B. (ed.), Brazilian Network on Green Chemistry: Awareness, Responsibility and Action, Editora UFC, 2008.

46. http://www.fao.org/docrep/010/ai466e/ai466e07.htm, acessado em Março de 2009.

47. Oliveira, M.; Pesquisa FAPESP 2008, 154, 29.

48. Kollonitsch, V.; Sucrose Chemicals, International Sugar Research Foundation, Washington D.C., 1970.

49. Paiva, L. M. C.; Programa de Sucroquímica UPSQ / DPN / INT, Instituto Nacional de Tecnologia, RJ, 1983.

50. Promon Engenharia S.A.; Subsídios para Implantação de uma Indústria Sucroquímica em Pernambuco, Recife, 1981.

51. Buchholz, K. E.; Stoppok, E.; Matalla, K.; Reh, K. D.; Jördening, H. -J.; Carbohydrates as Organic Raw Materials, Lichtenthaler, F. W. Ed.; VCH Verlag, NY, 1991, 155.

52. James, C. E.; Hough, L.; Khan, R.; Prog. Chem. Org. Nat. Prod. 1989, $55,117$.

53. Rosenthal, F. R. T.; Informativo do INT 1988, 17, 30.

54. http://www.encyclopedia.com/doc/1E1-oxalicac.html, acessada em Março de 2009.

55. http://chemicalland21.com/industrialchem/functional\%20Monomer/ ACRYLIC\%20ACID.htm acessada em Março de 2009.

56. http://www.lenzing.com/chemicals/en/products/2470.jsp acessada em Março de 2009.

57. http://chemicalland21.com/specialtychem/perchem/ITACONIC\%20 ACID.htm acessada em Março de 2009.

58. Santos, A. M.; Oliveira, M. P.; Giordani, D. S.; Eur. Polym. J. 2006, 42, 1196.

59. Dumbrepatil, A.; Adsul, M.; Chaudhari, S.; Khire, J.; Gokhale, D.; Appl. Environ. Microbiol. 2008, 74, 333. 
60. Sunitha, I.; Rao, K. J.; Ayyanna, C.; Bioproc. Biosyst. Eng. 1997, 18 55.

61. Salusjärvi, T.; Povelainen, M.; Hvorslev, N.; Eneyskaya, E. V.; Kulminskaya, A. A.; Shabalin, K. A.; Neustroev, K. N.; Kalkkinen, N.; Miasnikov, A. N.; J. Appl. Microbiol. Biotech. 2004, 65, 306.

62. Klasen, R.; Bringer-Meyer, S.; Sahm, H.; Biotechnol. Bioeng. 2004, 40, 183.

63. Ferreira, V. F.; Nakamura, T.; Nakamura, L. M. K.; Ferreira, C. M.; An. Acad. Bras. Ciênc. 1990, 62, 13; Ferreira, V. F.; Ferreira, C. M.; Nakamura, L. M. K.; Paiva, L. M. C.; Esteves, A. M. L.; Souza, V.; Revista de Química Industrial 1989, 56, 13.

64. Ferreira, V. F.; Paiva, L. M. C.; Esteves, A. M. L.; Starch-Starke 1986, 38, 173.

65. Patil, N. S.; Dordick, J. S.; Rethwisch, D. G.; Biomaterials 1996, 17 2343; Chen, J.; Park, K.; Carbohyd. Polym. 2000, 41, 259; Shantha, K. L.; Harding, D. R. K.; J. Appl. polymer Sci. 2002, 84, 2597.

66. Evans, P. J.; Wang, H. Y.; Appl. Environ. Microbiol. 1988, 54, 1662.

67. Dextran é um grupo de polissacarídeos de alta massa molecular composto de cadeias de unidades D-glicose que são sintetizados a partir de sacarose.

68. Roller, S.; Dea, I. C. M.; Critical Rev. Biotechnol. 1992, 12, 261; Qader, S. A. U.; Iqbal, L.; Aman, A.; Shireen, E.; Azhar, A.; Turk. J. Biochem. 2005, 31, 21; Sarwat, F.; Qader, S. A. U.; Aman, A.; Ahmed, N.; Int. J. Biol. Sci. 2008, 4, 379.

69. Reynolds, R. C.; Chappel, C. I.; Food Chem. Toxicol. 1998, 36, 81.

70. Sachinala, N. D.; Litt, M. H.; US Patent 5646226, 1997.

71. Sachinvala, N. D.; Winsor, D. L.; Menescal, R. K.; Ganjian, I.; Niemczura, W. P.; Litt, M. H.; J. Polymer Sci., Part A: Polym. Chem. 1998, 36, 2397.

72. Vogel, M.; Sciweck, H.; Rapp, K.; Chem. Ind. 1988, 288.

73. Ferrenbach, C.; Henkel-Referate Int. Ed. 1985, 21, 27.

74. Hough, L.; Int. Sugar J. 1989, 91, 23.

75. Frisch, K. C.; Kresta, J. E., Sucrochemistry: An Overview of Sugar Uretanes, Gould, R. F., Ed.; ACS Symposium Series 41, 238, 1977.

76. Thévenet, S.; Wernicke, A.; Belniak, S.; Descotes, G.; Bouchu, A.; Queneau, Y.; Carbohyd. Res. 1999, 318, 52

77. Ferreira, V. F.; Nakamura, T.; Rosenthal, F. R. T.; Ghiotti, A. M. T.; Pérez, L. M.; Santos, H. A.; Informativo do INT 1986, 18, 8.

78. Bazin, H. G.; Polat, T.; Linhardt, R. J.; Carbohydr. Res. 1998, 309, 189.

79. Nogueira, C. M.; Côrrea, A. G.; Bueno, O. C.; Resumos da $27^{a}$ Reunião Anual da Sociedade Brasileira de Química, Salvador Brasil, 2004.

80. Mackenzie, K. M.; Tisdel, P. J.; Hall, R. L.; Boysen, B. G.; Field, W. E.; Chappel, C. I.; Food Chem. Toxicol. 1998, 36, 111.

81. Reynolds, R. C.; Food Chem. Toxicol. 1998, 36, 95

82. Kunz, M.; em Sucrose to semi synthetical polymers, Descostes, G.; Ed.; VCH, 1993.

83. Cheng, G. X.; Liu, J.; Zhao, R. Z.; Yao, K. D.; J. Appl. Polym. Sci. 1998, $67,983$.

84. Hill, R. J.; J. Colloid Interface Sci. 2007, 316, 635.

85. Zhang, J.; Wang, A.; React. Funct. Polym. 2007, 67, 737.

86. Chen, X.; Dordick, J. S.; Rethwisch, D. G.; Macromolecules 1995, 28, 6014.

87. Hoffman, A. S.; Adv. Drug Deliv. Rev. 2002, 43, 3; Pourjavadi, A.; Harzandi, A. M.; Hosseinzandeh, H.; Eur. Polym. J. 2004, 40, 1363; Mooney, D.; Lee, K. Y.; Chem Rev. 2001, 101, 1869.

88. Ferreira, L.; Vidal, M. M.; Geraldes, C. F. G. C.; Gil, M. H.; Carbohydr. Polym. 2000, 41, 15

89. Zief, M.; Yanovsky, E.; Ind. Eng. Chem. 1949, 41, 1697.

90. Hough, L.; Phadnis, S. P.; Khan, R.; Jenner, M. R.; Brit. Pat. 1.543.167, 1977. (CA 87: 202019v).

91. Khan, R. em Sucrose. Properties and applications; Mathlouthi, M.; Reiser, P., Eds.; Blackie Academic \& Professional: Glasgow, 1995, cap. 11.
92. Mann, S. W.; Yuschak, M. M.; Amyes, S. J. G.; Aughton, P.; Finn, J. P.; Food Chem. Toxicol. 2000, 38, S91.

93. Para uma revisão recente sobre Isomaltulose: Kawaguti, H. Y.; Sato, H. H.; Quim. Nova 2008, 31, 134.

94. Schiweck, H.; Steinle, G.; Muller, L.; Gau, W.; Munir, M.; US pat. 4,233,439 1980

95. Kakinuma H.; Yuasa H.; Hashimoto H.; Carbohyd. Res. 1998, 312, 103.

96. Peltroche-Llacsahuanga, H.; Hauk, C. J.; Kock, R.; Lampert, F.; Luttikken, R.; Haase, G.; J. Dent. Res. 2001, 80, 378.

97. Lina, B. A. R.; Jonker, D.; Kozianowski, G.; Food Chem. Toxicol. 2002, $40,1375$.

98. Kawai, K.; Yoshikawa, H.; Murayama, Y.; Okuda, Y.; Yamashita, K.; Horm. Metab. Res. 1989, 21, 338.

99. Kunz, H.; Roger, H.; Puke, H.; Zuckerind 1990, 115, 174.

100. Kieboom, A. P. G.; Bekkum, van H.; Food. Sci. Technol. 1985, 14 , 263.

101. Kieboom, A. P. G.; Bekkum, van H.; Starch-Starke 1986, 38, 95.

102. Chheda, J. N.; Roman-Leshkov, Y.; Dumesic, J. A.; Green Chem. 2007, 9, 342 .

103. Chheda, J. N.; Dumesic, J. A.; Catal. Today 2007, 123, 59.

104. Nothenberg, M.; Química e Derivados 1994, set., 24.

105. Stodola, F. H.; Sharpe, E. S.; Koepsell, H. J.; J. Amer. Chem. Soc. 1956, $78,2514$.

106. Bourne, E. J.; Hutson, D. H.; Weigel, H.; Biochem. J. 1961, 79, 549.

107. Schwengers, D.; Benecke, H.; US Patent 4693974, 1978.

108. van Heeswijk, W. A. R.; Wassenburg, F. R.; Vliegenthart, J. F. G.; Carbohyd. Res. 1978, 62, 281.

109. Roper, von H.; Koch, H.; Starch-Starke 1988, 40, 121.

110. Roper, von H.; Koch, H.; Beck, R.; Starch-Starke 1993, 45, 121.

111. Lichtenthaler, F. W.; Angew. Chem. Int. Ed. Engl. 1992, 31, 1541.

112. Lichtenthaler, F. W.; Eur. J. Org. Chem. 2002, 4095.

113. Lichtenthaler, F. W. Em Methods and Reagents for Green Chemistry: An Introduction; Eds. Tundo, P.; Perosa, A.; Zecchini, F.; John Wiley \& Sons. Inc., 2007, 23.

114. Röper, H.; Starch-Stärke 2002, 54, 89

115. Hanessian, S.; Total Synthesis of Natural Products. The Chiron Approach, Pergamon Press, Oxford, 1983.

116. Stevens, C. V.; Industrial Products from Carbohydrates, Wood and Fibres em Renewable Bioresources - Scope and Modification for Nonfood Applications; Eds. Stevens, C. V.; Verhé, R.; John Wiley \& Sons. Inc., 2004, 160

117. Kunz, H.; Ruck, K.; Angew. Chem. Int. Ed. Engl. 1993, 32, 336

118. Ferreira, V. F.; Pérez, L. M.; Nakamura, T.; Nakamura, L. K.; Pat. Brasil $9201473, \mathbf{1 9 9 2}$

119. Wit, G. D.; Vlieger, J. J. D.; Kockvandalen, A. C.; Kieboom, A. P. G.; Vanbekkum, H.; Tetrahedron Lett. 1978, 15, 1327.

120. Hepner, L.; Carbohydrate feedstock for the fermentation industry, Associates Ltda, London, 1988.

121. Ferreira, V. F.; Nakamura, T.; Espíndola, L.; Nota Técnica INT/UPSQ, 1987, 4.

122. Jouillé, M. M.; Chen, S. Y.; Bhat, K. L.; Heterocycles 1985, 23, 691.

123. Jouillé, M. M.; Lin, W. R.; Han, S. Y.; Tetrahedron Lett. 1992, 33, 3595.

124. Vlahov, I. R. ; Vlahov, I. V.; Schimidt, R. R.; Tetrahedron: Asymmetry 1993, 4, 293

125. Schineider, B.; Lichtenthaler, F. W.; Steinle, G.; Schiweck, H.; Liebigs Ann. Chem. 1985, 2443.

126. Pinheiro, S.; Pedraza, S. F.; Peralta, M. A.; Carvalho, E. M.; Farias, F. M. C.; Ferreira, V. F.; J. Carbohydr. Chem. 1998, 17, 901.

127. Costa, P. R. R.; Ferreira, V. F.; Alencar, K. G.; Filho, H. C. A.; Ferreira, C. M.; Pinheiro, S.; J. Carbohydr. Chem. 1996, 15, 691.

128. da Silva, F. C.; Ferreira, V. F.; Perrone, C. C.; Quim. Nova 2001, 24, 905 
129. Bell, D. J.; J. Chem. Soc. 1947, 1461.

130. Raaijmakers, H. W. C.; Arnouts, E. G.; Zwanenburg, B.; Chittenden, G. J. F.; Carbohydr. Res. 1994, 257, 293.

131. Chan, J. Y. C.; Cheong, P. P. L.; Hough, L.; Richardson, A. C.; J. Chem. Soc., Perkin Trans. 1 1985, 1447.

132. Peters, S.; Lichtenthaler, F. W.; Lindner, H. J.; Tetrahedron: Asymmetry 2003, 14, 2475.

133. Lichtenthaler, F. W.; Klotz, J.; Flath, F.-J.; Liebigs Ann. Chem.1995, 2069.

134. Lichtenthaler, W. F.; Hahn, S.; Flath, F.-J.; Liebigs Ann. 1995, 2081.

135. Catal, T.; Li, K.; Bermekc, H.; Liu, H.; J. Power Sources 2008, 175, 196.

136. Utiliza-se este termo para designar certas secreções açucaradas, secas, exsudadas dos tecidos vegetais. De modo geral, as farmacopéias descrevem como maná a secreção originada do Fraximus ornus, espécie de freixo da região mediterrânica cultivada desde há séculos na Sicília e Calábria.

137. Costa, A. F.; Farmacognosia, Vol. II $5^{\text {a }}$ ed., Fundação Calouste Gulbenkian: Lisboa, 2002.

138. Oliveira, P. S. M.; Ferreira, V. F.; de Souza, M. V. N.; Quim. Nova 2009, $32,441$.

139. A forma medicamentosa do D-manitol é conhecida como Osmitrol $®$ e, em geral, é uma solução aquosa entre 15 a $25 \%$.

140. Archer, D. P.; Freymond, D.; Ravussin, P.; Ann. Fr. Anesth. 1995, 14, 77.

141. Duchateau, F. X.; Burnod, A.; Chollet, C.; Ricard, H.; Samain, E.; Marty, J.; Ann. Fr. Anesth. 2004, 23, 879.

142. Britto, M. A. F. O.; Jr., N. C. S.; dos Santos, H. F.; Quim. Nova 2004, 27, 882 .

143. http://www.portaldosfarmacos.ccs.ufrj.br/resenhas_ciclodextrinas.html acessada em Março 2009.

144. Villiers, A.; Compt. Rend. 1891, 112, 536.

145. Schardinger, F.; Z. Untersuch Nahr. U. Genussm. 1903, 6, 865.

146. Saenger, W.; Angew. Chem. Int. Ed. Eng. 1980, 19, 344.

147. Connors, K. A.; Chem. Rev. 1997, 97, 1325.

148. Hedges, A.; Chem. Rev. 1998, 98, 2035.

149. Singh, M.; Sharma, R.; Banerjee, U. C.; Biotech. Adv. 2002, $20,341$.

150. Li, S.; Purdy, W. C.; Chem. Rev. 1992, 92, 1457.

151. Ferreira, L. F. V.; Lemos, M. J.; Wintgens, V.; Netto-Ferreira, J. C.; Quim. Nova 1999, 22, 522.

152. Lindner, K.; Saenger, W.; Carbohyd. Res. 1982, 99, 103.

153. Engeldinger, E.; Armspach, D.; Matt, D.; Chem. Rev. 2003, 103, 4147.

154. Szejtli, J.; Chem. Rev. 1998, 98, 1743; Wenz, G.; Angew. Chem. Int. Ed. Engl. 1994, 33, 803; Chankvetadze, B.; Endresz, O.; Blashke, G.; Chem. Soc. Rev. 1996, 25, 141; Arad-Yellin, R.; Tsoucaris, G.; Green, B. S.; Tetrahedron Lett. 2001, 42, 1335; Al-Sherbini, E. A. M.; Micropor. Mesopor. Mat. 2005, 85, 25; Gilbert, B. C.; Smith, J. R. L.; Taylor, P.; Ward, S.; Whitwood, A. C.; J. Chem. Soc. Perkin Trans. 2 2000, 2001; Lim, C. W.; Sakamoto, S.; Yamaguchi, K.; Hong, J.; Org. Lett. 2004, 6, 1079; Park, K. K.; Kim, Y. S.; Lee, S. Y.; Song, H. E.; Park, J. W.; J. Chem. Soc. Perkin Trans. 2 2001, 2114; Abou-Zied, O. K.; Spectrochim. Acta, Part A 2005, 62, 245; Bardelang, D.; Rockenbauer, A.; Jicsinszky, L.; Finet, J. -P.; Karoui, H.; Lambert, S.; Marque, S. R. A.; Tordo, P. J. Org. Chem. 2006, 71, 7657; Liu, Y.; Zhang, N.; Chen, Y.; Chen, G. -S.; Bioorg. Med. Chem. 2006, 14, 6615.
155. Nicollazzi, C.; Abdou, S.; Collomb, J.; Marsura, A.; Finance, C.; Bioorg. Med. Chem. 2001, 9, 275; Dubes, A.; Degobert, G.; Fessi, H. ; ParrotLopez, H.; Carbohyd. Res. 2003, 338, 2185.

156. Loftsson, T.; Masson, M.; Int. J. Pharm. 2001, 225, 15.

157. Tabushi, I.; Acc. Chem. Res. 1982, 15, 66.

158. Ortega-Caballero, F.; Gimenez-Martinez, J. J.; Vargas-Berenguel, A.; Org. Lett. 2003, 5, 2389.

159. Breslow, R.; Acc. Chem. Res. 1995, 28, 146.

160. Breslow, R.; Dong, S. D.; Chem. Rev. 1998, 98, 1997.

161. Easton., C. J.; Lincoln, S. F.; Chem. Soc. Rev. 1996, 25, 163.

162. Breslow, R; Kool, E.; Tetrahedron Lett. 1988, 29, 1635.

163. Breslow, R.; Hammond, M.; Lauer, M. J.; J. Am. Chem. Soc. 1980, 102, 421; Breslow, R.; Canary, J. W.; Varney, M.; Waddell, S. T.; Yang, D.; J. Am. Chem. Soc. 1990, 112, 5212.

164. Breslow, R.; Duggan, P. J.; J. Am. Chem. Soc. 1992, 114, 3982.

165. Fujita, K.; Chen, W. H.; Oiwane, K.; Fujioka, T.; Fukudome, M.; Yuan, D. Q.; Tetrahedron Lett. 2004, 45, 6899.

166. Buxton, I. L. O.; em Goodman \& Gilman, The Pharmacological Basis of Therapeutic. $11^{\mathrm{a}}$ ed. McGraw Hill, 2005.

167. Frank, D. W.; Gray, J. E.; Weaver, R. N.; Am. J. Pathol. 1976, 83, 367.

168. Davis, M. E.; Brewster, M. E.; Nat. Rev. Drug. Disc. 2004, 3, 1023.

169. Abulrob, A.; Tauskela, J. S.; Mealing, G.; Brunette, E.; Faid, K.; Stanimirovic, D.; J. Neurochem. 2005, 92, 1477.

170. http://www.gerbras.com.br/produtos/cycloazelon.asp acessada em Março 2009

171. http://www.farmalabchiesi.com.br/prescicladolefervescente.htm acessada em Abril 2008.

172. Loftsson, T.; Masson, M.; Int. J. Pharm. 2001, 225, 15; Szejtli, J.; Pure Appl. Chem. 2004, 76, 1825.

173. Venturini, C. G.; Nicolini, J.; Machado, C.; Machado, V. G.; Quim. Nova 2008, 31,360 .

174. Baird, C.; Environmental Chemistry, $2^{\text {nd }}$ ed., W. H. Freeman: New York, 1999.

175. Klein, C.; Schneider, R. J.; Meyer, M. T.; Aga, D. S.; Chemosphere 2006, 62, 1591.

176. Balmas, V.; Delogu, G.; Sposito, S.; Rau, D.; Migheli, Q.; J. Agric. Food Chem. 2006, 54, 480.

177. Romi, R.; Lo Nostro, P.; Bocci, E.; Ridi, F.; Baglioni, P.; Biotechnol. Prog. 2005, 21, 1724.

178. Arad-Yellin, R.; Tsoucaris, G.; Green, B. S.; Tetrahedron Lett. 2001, 42, 1335.

179. Tsorteki, F.; Bethanis, K.; Pinotsis, N.; Giastas, P.; Mentzafos, D.; Acta Crystallogr., Section B: Struct. Sci. 2005, 61, 207.

180. Szaniszló, N.; Fenyvesi, É.; Balla, J.; J. Inclusion Phenom. Macrocyclic Chem. 2005, 53, 241; Villaverde J.; Morillo, E.; Pérez-Martínez, J. I.; Ginés, J. M.; Maqueda C.; J. Agric. Food Chem. 2004, 52, 864.

181. Dignam, C. F.; Randall, L. A.; Blacken, R. D.; Cunningham, P. R.; Lester, S. K. G.; Brown, M. J.; French, S. C.; Aniagyei, S. E.; Wenzel, T. J.; Tetrahedron:Asymmetry 2006, 17, 1199.

182. Del Valle, E. M. M.; Process Biochem. 2004, 39, 1033.

183. Loftsson, T.; Leeves, N.; Bjornsdottir, B.; Duffy, L.; Masson, N.; J. Pharm. Sci. 1999, 88, 1254.

184. Tobitsuka, K.; Miura, M.; Kobayashi, S.; J. Agric. Food Chem. 2005, 53,5402 .

185. Wang, C. X.; Chen, S. L.; Fibres Textiles Eastern Eur. 2005, 13, 41. 